\title{
HOW CAN WE TEACH FOREIGN LANGUAGES IN THIS POST-PANDEMIC DIGITALIZED AND GLOBALIZED WORLD?
}

\author{
Prof. Ph.D. Jacques COULARDEAU
}

Université Paris 1 Panthéon-Sorbonne, 8 rue de la Chaussée, 63880 Olliergues, FRANCE,

E-mail: dondaine@orange.fr

\begin{abstract}
1- What are foreign languages? First language, second language, Bilingualism.

2- Foreign language and the learner's age

Before 6 - after 6 - after 12 - grown up (after 18, and older)

3- Halliday, Notional Functional, and the EU

Halliday and extreme urgency in the 1960s of the Indian subcontinent's immigration to the UK. EU's Mistake. Denis Girard's double mistake. Languages are easier to learn if there is any urgency and motivation.

4- How can we create urgency for foreign languages in a school environment?

$a$ - The top best: Virtual Reality.

$b$ - Chatbot and Artificial Intelligence.

c- Telephone: one-on-one student-teacher on a previously assigned or chosen document or subject.

$d$ - Balancing act: machine or teacher vs student/students (no more than three). In presential one-on-ones or several-on-ones versus distant learning/teaching. The use of Artificial Intelligence - Facial recognition cameras - capturing body and facial language.

$e$-All along we have to understand that the learners have to be encouraged to speak of what they like or dislike, and the teacher must be able to follow and respond to the requests and provocation of the students.

5- Beyond the pandemic

a- The mistake: to go back to what it was before. The pandemic must be seen as an opportunity.

b-Teaching foreign languages: a Public-Private Partnership (PPP), with UNESCO, UNICEF, all companies dealing with the hardware, software, and similar projects.
\end{abstract}

Keywords: Virtual Reality; COVID-19; Foreign Languages; School Education; Further Education; Distant Learning;

\section{INTRODUCTION}

It seems to me that it would be good to raise the problem of languages in today's Europe both as languages of Europe, present in Europe for thousands of years for the most part, and languages in Europe which have only been present in Europe since the migration movements which concern the arrival of non originally European populations for at least a century (since the First World War).

The problems are partly the same, languages of identification and languages of daily exchanges within diverse communities. But as much as the languages of Europe are recognized in domains such as education, everyday communication, local, national, or European administration, the languages in Europe are not recognized at these various levels 
and thus are a background of frustration, even of demands if not of rebellion, accumulates and builds up most of the time at the local or regional level.

The languages in Europe that are not of European origin bring up a much greater problem. The languages of Europe are all Indo-European languages (spreading in Europe after 10,000 BCE in the Magdalenian), except of course the agglutinative languages such as Hungarian (an inner European migration before the $10^{\text {th }}$ century since the earliest known written Hungarian words are to be found in a Latin document, the Foundation Charter of the Abbey of Tihany, 1054), Finnish, Estonian, Lappic, and Basque, plus a few others in the north of Russia, in the Urals, in the Caucasus, and of course in Siberia (all arrived long before the peak of the Ice Age, somewhere around 50,000 BCE, at least), but Siberia is clearly outside Europe. Note that some of the immigrant languages are of the same two families: Turkish is agglutinative, and Kurdish is Indo-European. But most of the languages of immigrants since 1920 are languages of very different linguistic families. Semitic or Afro-Asiatic languages, especially Arabic, Kabyle/Berber, and some others from North Africa and the Middle East. Various African languages. Various Asian languages. All languages carry within them a frame of thinking and culture. The frame of thinking is absolutely unconscious for the speakers of these languages. They think the way they speak, and sometimes write. On the other hand, the cultures that these languages carry are most of the time conscious, claimed, and identifying. The lack of consideration for these languages and the cultures they carry in too many instances of our societies, and in the first place, education, and administration, is the most important cause of a malaise that leads here and there to crises, sometimes violent crises, or criminal initiatives.

The only answer to these situations is the recognition of the plurilingualism of all the languages of Europe and in Europe, and the acceptance of all the cultures that all these languages carry, and this poses the problem of our understanding of the frames of thinking that the languages carry within their own syntaxes and lexicons, and how these psycholinguistic operations are articulated on the cultures of the very communities that speak the concerned languages. It must be very clear that these migrant populations must master at least three languages to find their way in our world: their first language (and sometimes this implies two languages: Arabic and Kabyle, or two African languages, due to the original mass bilingualism of these migrant populations); the vernacular language of communication of the country where they are; and English most often as the international language of the increasing professional necessity in the various industries and economic activities of our countries. This is much more complex than the simple multilingualism of the original Europeans and their European languages.

And this is not recent. I knew a young Algerian Kabyle woman in Roubaix (Kabyle like the majority of Algerians in Roubaix) who was able to switch from Kabyle to Arabic, then from French to Roubaisian Picard, and adding some English from her secondary education. She always tried to address people in their first language, and this posed problems for communication in equally multilingual groups, as for the multiplicity of their first languages and not necessarily their command of this multilingualism. In this direction, there is an important work to be done on the psycholinguistics that underlies these situations and this can only be done in an applied way, avoiding the mistakes made in the past, such as in Normandy some time ago where an initiative of teaching Turkish was set up for an immigrant population from Turkey, without wondering if the first language of these immigrants was Turkish or Kurdish. And it was Kurdish, hence a total failure of the initiative. And what about the case of Aisha in first grade who was able, in the neighborhood 
committee's extracurricular support group, to read - even with her book closed - the page of reading studied during the day and to work on for the next day. She had memorized the page, and when she was asked to go back to the previous page or even a little further back to what she had worked on over the previous days, she was unable to read, even with her book closed. Imagine the frustration of this little girl who was convinced she could read. Imagine the drama a few years later when her parents would take her along to read for them various forms or notices in some administrative procedure.

When these young people reach the age when they want to say no to such situations, they realize that they are not heard, that they are not listened to, that they are not understood. What is left for them to do in order to be heard? And in return, how can we make ourselves heard by them if we do not speak the same language, the same psycho-language because language is much more than just words, or even sentences. It would be in our interest to put the most advanced approaches of psycholinguistics, psychomechanics, and cognitive linguistics back on the desk, on the worktable, on the workbench itself. This is a whole program to be developed at the level of the applied experiential, and existential practices of the local communities concerned. And what about the national or European communities?

The problem I want to examine here is the teaching of foreign languages to all our European populations that can only imagine, so far, they can prosper if they only stick to one language that they generally call their mother tongue. This problem is vastly amplified by, first of all, the globalization of the world, and second, by the consequences of the COVID19 pandemic that both boost the necessity to consider all problems at the level of the whole planet since viruses do not know borders, on one hand, and these viruses may widen the scope of migrations both in geographical reach and in numbers to escape the non-vaccinated areas and to reach the zones where the vaccines are vastly present, on the other hand. And they are actually spreading the virus and its variants when doing that. And we have to keep in mind war zones, poverty zones, underdeveloped countries are wide open to the virus and its variants, and they are also out of reach because they cannot afford the vaccines and the local conditions make vaccination difficult, at times impossible.

This will bring large demographic movements, and the need to possess several languages, both for the migrating populations and for the populations of the countries targeted by them, hence for us, Europe, particularly western and central Europe, and be sure Brexit will be no protection at all. How can we cope with this need for at least bilingualism if not multilingualism?

And that's where COVID-19 is a tremendous incentive to innovate. I am going to explore some of the avenues of this possible innovation.

\section{FAST PRELIMINARY TOPICS}

1- What are foreign languages? First language, second language, Bilingualism.

The first preliminary question is about the definition of languages in a multilingual society. The term "mother tongue" is definitely no longer true. Too many people live in bilingual or multilingual environments. The language or languages the child heard in his mother's womb after the $24^{\text {th }}$ week of pregnancy is of course the language of the mother but also the language or languages of the people speaking to the mother, and the mother might be bilingual herself. When the child is born, he will hear the language of his or her mother, or eventually the two languages the mother might speak, plus the language of the maternity personnel and later the creche personnel, and this language might be one of the languages he had heard before being born. It is then fair enough to speak of the first language and the 
second language for a bilingual child. The first language might be the language of the mother or the language of the father or even the language of the surrounding community, like the personnel of the creche, then kindergarten, then grade school. A child in a Kabyle family in Roubaix is confronted with Kabyle as the dominant language of the family, but also Arabic since the religion of this family is Islam, hence is in Arabic. The family is bilingual as for these two languages, but in Roubaix, the dominant language outside this family is French, and/or some creolized form of either Picard which is the old urban popular language of the city still spoken in various creolized levels, or some creolized form of French that includes some Picard (words, pronunciation, syntax). The Picard language has a special verb for this practice of trying to speak proper French though the result is a creolized form of Picard and French. The verb is "s'aparler" meaning that someone is trying to speak the dominant language but fails and produces some kind of mashed-up language which is for the speaker proper French, though it is not and the speaker most of the time does not know it is not, except when some people around him make fun of his "dialect" or "patois" meaning "bastardized" French, and it is derogatory.

A bilingual child or person is a person who can shift from one language to another freely and fluently according to the situation around them. Normally there is not a first or second language for a bilingual person: the two languages are equal.

\section{2- Foreign language and the learner's age}

The second question is the learning situation of a foreign language for a person according to their age. A foreign language is normally not one of the two languages of a bilingual child. For him or her a foreign language is a third language. A bilingual child taking classes in one of the two languages they already control is cheating with the concept of foreign. It might be a foreign language for the concerned society or country, but it is not for the bilingual child. When you have a bilingual child in a foreign language class that teaches one of the two languages of the bilingual child, the child has to be used intelligently, hence as someone who knows the language and can become a tutor for his classmates. This is not that complicated, and any foreign language teacher should be able to use the bilingual child, except if this teacher feels insecure if not endangered by the bilingual child who might know more than he/she does. An English teacher in Ambert, France, High School once had a bilingual child just coming back from the USA, aged 17, and she said something wrong. The student corrected her. She sent him to the library with another student to make sure he went there, and he actually checked the word he criticized. And I should say, of course, the bilingual student was right. He came back to the class with his accompanying chaperon, and both told the bad news. The bilingual student was right, and the teacher was wrong.

Before 6 years of age, a child can easily learn a foreign language through simple imitation (and the earlier the better). The best way then is to use stories and nursery rhymes that are repeated by the children in a way or another. Songs are ideal and the children will easily follow, including taking part in a vocal or singing confrontation of two or three groups representing different characters and taking part in the exchange that becomes some kind of challenge, competition. This is very easy in kindergartens and when they reach the age of five, they can even become creative, assume personae that become real characters. We all know Rossini's "Duetto para dos Gatos - Duet for Two Cats" (check what it can become at https://www.youtube.com/watch?v=FJDtCw0MTNU) and you can easily make young children under six play with words and have duets or even more than two voices and make them sing and play with simple nursery rhymes like The Farmer in the Dell: 
The farmer in the dell $(2 \mathrm{x})$

Hi-ho, the derry-o...

The farmer in the dell

The farmer takes the wife $(2 \times)$

Hi-ho, the derry-o...

The farmer takes the wife
The wife takes the child $(2 \times)$

Hi-ho, the derry-o...

The wife takes the child

The child takes the nurse $(2 \times)$

Hi-ho, the derry-o...

The child takes the nurse $[\ldots]$

Imagine what it could become if the children were encouraged to compose their own songs like "My mother in the yard..." or "My brother in the street..." or "My sister in the car..." or "My father on the roof..." And imagine the students in a "zoom-like situations with all the faces on a screen and each student being able to see them all, face-to-face, including himself, while he is singing in and to a mosaic of twelve or more faces doing the same. This requires some psycholinguistic and pure psychological exploration and research. In this mirror-like situation Lacan's mirror stage is multiplied by the number of faces around that of each particular child and his knowledge that he is being scrutinized by all these other singers. The children are acting singers, and at the same time the director of it all watching the performance. Each child is a conscious acting singer, the member of an acting and singing group, and the meta-spectator watching himself surrounded by the others. This type of learning technique can be used systematically with children under six, but it can also be used with older children, though as some kind of "entertainment" in the class. I remember making seventeen-year-old children sing for fun a humorous version of "God Save The Queen" for Halloween with a real eviscerated pumpkin on the desk with a candle inside.

God Save Our Dear Pumpkin

God Save Our Dear Pumpkin

God Save Pumpkin, etc.

No disrespect in it since the music is by Jean-Baptiste Lully on words by the headmistress, Madame de Brinon, of the Royal Girls School of Saint Cyr, written as a prayer when Louis XIV had to go through a surgical intervention by Charles-Francois Felix de Tassy, the barber-surgeon of the court in Versailles in 1686. It was sung for the first time in London in 1745. This version of the story can be questioned and there are older popular versions before the one for Louis XIV.

After the age of six things can change because between six and twelve children develop their conceptualizing power with simple things, objects, and notions, but also with the discovery of the first levels of mathematics and physics, or even other experimental sciences, not to forget the surrounding environment of the children that can be either urban or rural or at times both. If the students have never been in real active and operational contact with a second or third language, they might find it difficult to enter the pronunciation or syntax of the new language, but before puberty language is less important as an identifying characteristic, though it may be for children coming from an immigrating population, but it is most of the time a mistake to go on only using games and songs, and other playful techniques. We must keep in mind that only about an estimated $10 \%$ of all people can naturally learn any foreign language by pure imitation and direct fast assimilation. This is an estimation. But children who are classified (I do not say diagnosed) Asperger children, one form of autism, the savant autistic personality, can learn in such a mimetic way at a very fast speed and we have not studied it enough to know the mental processes of these children. (Check Daniel Tammet, Born on a Blue Day: Inside the Extraordinary Mind of an Autistic 
Savant, Free Press, October 16, 2007). Some stricter drills can be introduced after six, though these drills can remain playful or entertaining. But the main objective might be descriptive. Descriptive of videos in English with the strong objective of transcribing, orally with questions and answers, the dialogue of these videos. Films like cartoons can be one easy approach because the pictures provide a lot of understanding that helps the capture of the words. Imagine what it could be in a Virtual Reality situation or world. Let's take a stroll in London and let's discover and describe the buildings, the people, etc. The teacher is essential to make the children speak English and not their first language in such a situation. The group should be limited. Of course, we can even inject an Artificial Intelligent guide that can ask the questions and even answer some questions knowing that this virtual guide can only understand and speak one language, English.

Today with facial recognition cameras we can follow each student in this virtual reality London and identify what attracts their vision and what their emotions might be, and the Artificial Intelligent guide can be guided in his interchanges with the students by this data. You could maybe make the visit more attractive with - if intellectual property rights permit it - meeting the Queen in Windsor Castle or Buckingham Palace. Or what about discovering Shakespeare, Newton, and many others in Westminster Abbey. Children can learn how to swim naturally by jumping into the water because it is natural if the children have not been subconsciously informed with some kind of fear of water. If the children are not subconsciously hostile to the foreign language, they will naturally learn from their environment, even a virtual environment.

Jumping over the limit of twelve years of age into puberty and middle school, we have to deal with the fast-developing minds of fast-growing teenagers. That's when the children start developing some identity anxiety that makes them very reluctant to do things that may question their deeper reality that they would never express though it is, at worst, subconscious, but it is often absolutely conscious. All sorts of fears and appeals can develop in them. That's when it becomes crucial to make the students the masters of their studying environment and their academic topics, including the day-to-day work and pedagogical choices. They have to choose what is going to be done in the class, and they have to choose the videos, the topics they are going to work on. The limits might be on the teacher's side, limits coming from the law, from the school institutions, from the teacher's own convictions or impulses, not to speak of parents and colleagues, etc. As soon as twelve, the children must become their own pedagogical masters. Before they were only following what entertained them. Now they want to approve or disapprove, discuss, question, confront or reject what comes in front of them. And luckily, a group can never be homogeneous. My experience is that most kids accept the clearly expressed decisions of the group, not those of the teacher. Yet some might remain aloof. It is then suggested that subgroups be constituted in the class and these groups can be composed of students who have the same interests. No topic has no interest, and you can always build some rich exploration even of the most uninteresting films, videos, topics, books, or whatever. I have only been confronted in many years with one case of one Junior Highschool class asking to stop working on a film, Cool Runnings, they had chosen after only a couple of sessions because it became innocuous and boring very fast. But I never had any problem with films like Seven or American History X or Romeo + Juliet, and every sequence brought up new elements of culture and topics of discussion. What I say here is practically valid till the end of high school, though senior classes might jump into the next phase. 
When reaching eighteen, the students start, and at times very strongly because it has been brewing for two or three years with some students, to wonder what use the foreign language is going to be in their life. They start wondering if it is worth investing energy and work in such a subject. That's where immersion becomes essential. They have to be immersed in a professional situation and context to be interested. They have to do it for their own professional future and not for some kind of touristic interest that becomes at least secondary if not marginal. The great chance we have after this COVID-19 epidemic is that it is enabling us to realize that new techniques can be used. The way Virtual Reality is used to teach future pilots how to fly transcontinental liners, we can have the same kind of Virtual Reality to learn a language and we just have to alternate and diversify the situations and the objectives. But the students will always ask for things that are professionally oriented. Today, let's learn how to drive a bus with Mr. Driver X as the coach or accompanying tutor. Tomorrow let's be immersed in a traumatic situation of a bus the student, impersonating Mr. Driver X, is driving, and it falls into a serious accident with twenty people in the bus and their reactions to the accident, etc. On the following day let's just enjoy a bus trip from Bordeaux to Toulouse with four stops along the way and four different visits: (1) a vineyard in Langon, (2) an industrial tomato-growing farm in Marmande, (3) a stop in Agen and a prune drying factory, (4) a fourth stop in Montauban and a visit to a candy and chocolate maker like Les Délices Guy Pécou.

There are so many possibilities along such lines. And the interesting thing is that groups of twenty-five learners working together in a classroom are no longer the norm. The forty-five-year-old industrial executive who had negotiated with his employer a promotion provided he got the special graduate studies Intellectual Property Certification from Université Paris 2 Assas Panthéon was motivated to learn English, but we were only dealing with copyright laws and other documents on the subject of Intellectual Property (and I can speak from practice on such a subject being a vastly published author and an authors' union cadre). In the same class, the Chinese student from Peking University in Beijing did not know much French and was very average in English, but she had been sent to Paris to follow this graduate studies course by Mrs. Hu who was at the time responsible in Beijing for the development of the Internet. She was motivated to learn the copyright laws of the USA and other topics on this very subject. The unemployed adults, some over forty who had been fired from the textile industry in Roubaix and had been proposed some further education classes to get a two-year college certification were motivated to learn English, some of them from scratch because they wanted to get back to work. Only one way here, be concrete and professionally oriented. My training as a TOEIC instructor was quite useful. Actually, I used this qualification in a Junior High School class. They loved taking an authentic TOEIC test though they were Science and Mathematics students. But the professional dimension was for them the interest, the appeal, along with the use of recorded audio documents.

Nowadays, this professional dimension is becoming dominant and the new techniques I will discuss later in more detail are fundamental.

\section{3- Halliday, Notional Functional, and the EU}

As an appetizer here is an excerpt of the M.A.K. Halliday entry of the Encyclopedia Britannica (my highlighting in yellow and my red bold font).

"Drawing on Firth's work, Halliday came to see language as a social construction and, crucially, the mechanism by which society is reproduced and, occasionally, transformed. That insight, combined with his commitment to improving social conditions, left Halliday 
searching for a new way of teaching language to improve literacy rates and give ordinary people greater opportunities.

This socially focused approach put Halliday at odds with established figures on the 'nature' side of the 'nature or nurture' debate. They included Noam Chomsky and his followers, who believed the human [competence] for language was innate rather than acquired during life.

Halliday argued the key to language development lay in how children attribute "meaning" to elements in their environment. In contrast to Chomsky and his followers, who advocated an inherent universal human grammar, Halliday developed a theory of language based on a system of choices. The results were Halliday's models of systemic functional grammar and systemic functional linguistics."

We could question the sentences and phrases highlighted in yellow and particularly the one in bold red font because it implies children have the meaning of things before the names for them. They obviously have first the experience of things to which they attribute names that mostly come from their environment and that builds the mental meaning of the word and its reference. But here I would like to concentrate on the pedagogy that is derived from this particular cognitive linguistics. It is this pedagogy that was vastly implemented in the 1960s when Prime Minister Harold Wilson (Prime Minister from 1964 to 1970 and again from 1974 to 1976) accepted to consider the British passports that had been given to millions of people in Pakistan, India, and Bangladesh during the colonial era, gave these people the right to travel to Britain and register there as British citizens. The urgency that characterized the situation of these people in this massive migration was such that the pedagogy derived from M.A.K. Halliday's books was highly successful, maybe not always in the quality of the English acquired in such conditions, but as for the quantifiable amount of competence in social services, educational services, and all other community services these migrants had to integrate in a very short time. The effectiveness of this massive learning of English as an integrating requirement was quite admirable.

But I would like to give some details about this method from one book published later on in his life: M.A.K. Halliday's Introduction to Functional Grammar, Fourth Edition ${ }^{l}$. We could also refer to MAK Halliday, Angus McIntosh \& Peter Strevens, The Linguistic Sciences, and Language Teaching, 1964.

First of all, we have to really qualify M.A.K. Halliday as a linguist. His theory could be defined as applied discursive sociolinguistics. It is sociolinguistics because the theory is centered on the uses, and functions of language in the various social situations any language is turned into text, meaning in which a linguistic message is produced. This linguistic theory is a social science studying the linguistic behaviors of individuals in all sorts of social environments and communicational requests. It is a discursive theory because it only takes into account the discursive production of these messages. In fact, the "langue" (Ferdinand de Saussure's or Gustave Guillaume's concept as opposed to "parole" or "discourse" respectively) of the language concerned here, English, and of each individual speaker is never

\footnotetext{
${ }^{1}$ M.A.K. Halliday, Revised by Christian M.I.M. Matthiessen, Halliday's Introduction to Functional Grammar Fourth edition, Third edition published in 2004 by Hodder Education, a Hachette UK company. This fourth edition published in 2014 by Routledge 2 Park Square, Milton Park, Abingdon, Oxon OX14 4RN. Simultaneously published in the USA and Canada by Routledge 711 Third Avenue, New York, NY 10017. Routledge is an imprint of the Taylor \& Francis Group, an informa business (C) 1985, 1994, 2004, 2014 M.A.K. Halliday and Christian M.I.M. Matthiessen
} 
taken into account in its phylogeny and its psychological dimension. And it is applied because he only considers the analysis of actual messages and produced clauses or texts in their discursive existence. He only tries to identify the "effets de sens" ("effective meaning") of these finalized texts and how this "effective meaning" may change if the order of words changes, if intonation is added, if body language is also used. He does speak of notions as the targeted entities that are supposed to be cast in the texts that correspond to the functions of these texts in real discursive practice and situations. For Saussure, that's "parole" (speech). For Guillaume, that's "discours" (discourse). But we are missing the "langue" of Saussure and Guillaume (the abstract system of abstract systems that operates as a processing and producing machine or apparatus in the mind of the subject, even before he utters the slightest discursive word). We are missing Guillaume's "visée de sens" ("targeted meaning," and "notions" are too vague to satisfy this targeting that makes the speaker the real master of his speech) and we only have "effets de sens" ("effective meaning" with no explanation how the abstract system of abstract systems this langue is, produces these "effets de sens"). We thus end up with an exploded, scattered, multifarious of independent functions and values in these functions for the words used to evoke the notions. The figure used here speaks on its own (op cit, p. 37).

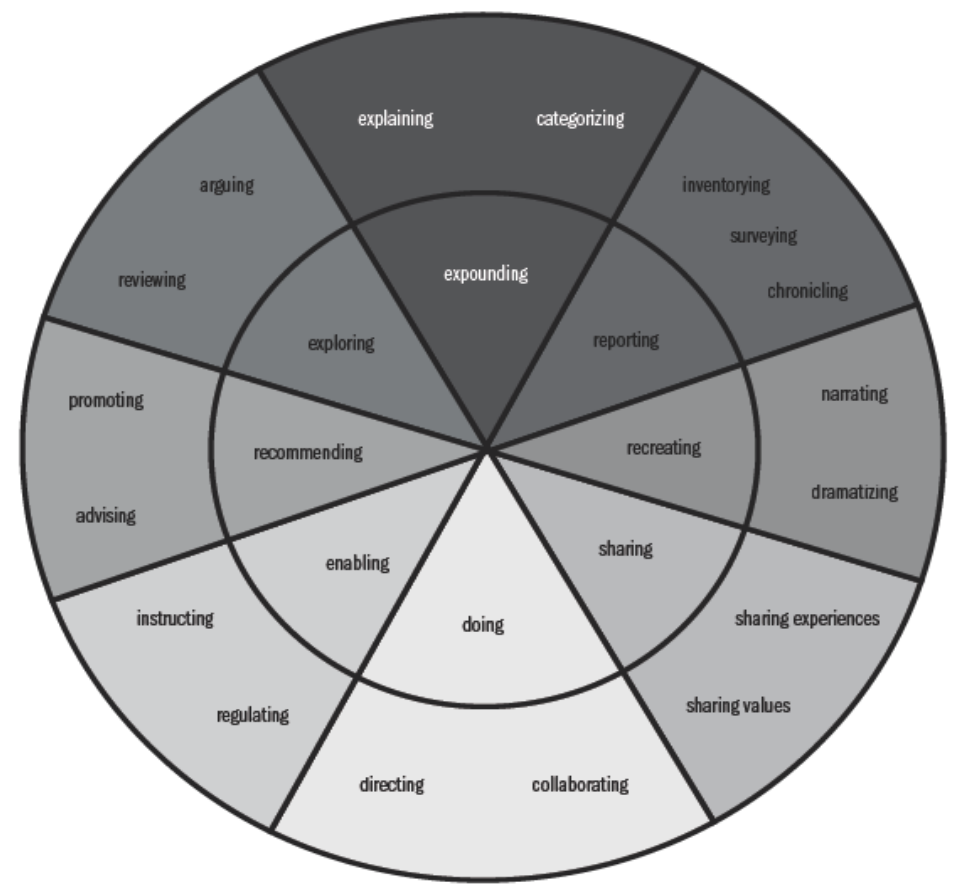

Fig. 1-13 Field - socio-semiotic process (activity) represented as a topology

And that's exactly what the teaching method is when you start from one notion, capability, and you implement it in all those situational functions and the only learning you have to do is rote learning of the particular texts you will produce to embody this particular notion in these particular functions. The abstract relations do not specify the syntactic functions of the elements these abstract relations bring together. It only specifies the "effets de sens," hence the discursive values. 


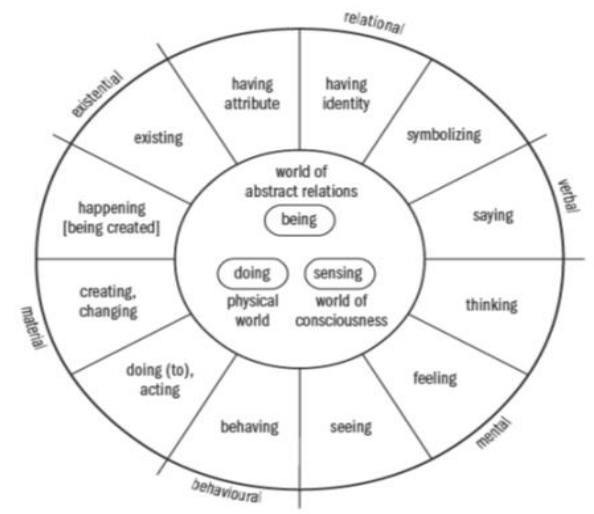

Flg. 5-3 The grammar of experience: types of process In English

And he goes one step further in this absence of "langue" and absence of "syntax" or "syntactic functions."

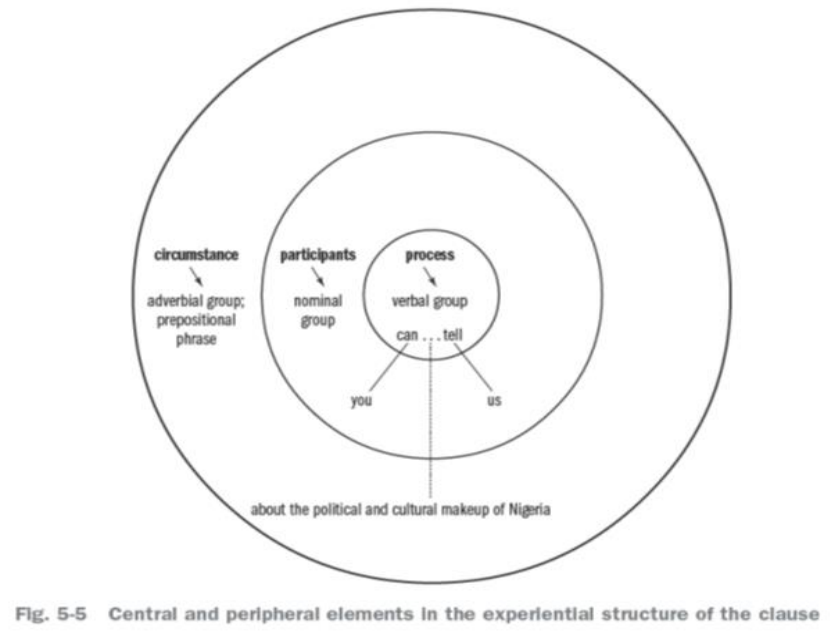

We never get the syntactic structure of the sentence which, by the way, is a question: "Can you tell us about the political and cultural makeup of Nigeria. He only proposes the following Figure:

\begin{tabular}{|l|l|l|l|l|}
\hline Can & you & tell & us & about the political and cultural makeup of Nigeria \\
\hline pro- & participant & -cess & participant & circumstance \\
verbal ... & nominal group & ... group & nominal group & prepositional phrase \\
\hline
\end{tabular}

Flg. 5-6 Clause as process, participants and clrcumstances

This experiential approach does not provide us with the syntactic functions that could enable the learner to produce a similar sentence or to play on the syntactic structure. It does not explain the originality of the question that can be considered either as a yes/no question or as an open question requiring a full answer "about the political and cultural makeup of Nigeria." "You" is the addressee/utteree of "us" who is the addresser/utterer of the question. The action "utter" is not mentioned, only implied ("we say" or "we ask"). The uttering is the whole sentence, here a question. The functional thematic structure is:

"you" (location) - can - "tell..." (theme)

"you" (agent, source) - tell - "us" (goal) - "about..." (theme) 
Instead of the stratified approach in which each and all stratum/strata has/have no phylogenetic relationships with the other strata, I prefer Ray Jackendoff's hierarchical syntactic tiered approach centered on the "temporal "elements" that express the processes in the sentence (generally considered as verbal elements in Indo-European and Turkic languages) because it establishes a certain number of analyses of one sentence, each one centered on one "verbal" element. That provides the learner with a unified approach of each utterance, though hierarchically tiered. My difference in this approach with Ray Jackendoff's is that he centers his analyses on the spatial "theme" element, the element that suffers or endures the "verbal" process, the element that is the basic "nominal" ergative element in an ergative language. I center my approach on the "verbal" elements considering that in a complex "verbal" phrase (that includes only "verbal" elements and no "nominal" predicative complements), each "verbal" element, be they auxiliaries, modals or simple verbs, has a syntactic thematic structure in the whole sentence. To call, in the previous example, the theme of the telling plain circumstances is unrealistic. It is not. It is the core of the telling, the matter the telling is about. The theme (nothing to do with the couple theme-rheme, but here it is the syntactic function put forward by Ray Jackendoff) is what is directly passively (what has to be told) - or rather non-actively (the matter that is going to be transferred from "you" to "us" if we consider "tell" is a verb of transfer) - concerned by the verbal process.

To complicate - for him to explore - further the situation, he proposes a stratified vision that captures these situations along three parameters (my emphasizing bold black and blue fonts):

"field - what's going on in the situation: (i) the nature of the social and semiotic activity; and (ii) the domain of experience this activity relates to (the 'subject matter' or 'topic')

tenor - who is taking part in the situation: (i) the roles played by those taking part in the socio-semiotic activity - (1) institutional roles, (2) status roles (power, either equal or unequal), (3) contact roles (familiarity, ranging from strangers to intimates) and (4) sociometric roles (affect, either neutral or charged, positively or negatively); and (ii) the values that the interactants imbue the domain with (either neutral or loaded, positively or negatively)

mode - what role is being played by language and other semiotic systems in the situation: (i) the division of labor between semiotic activities and social ones (ranging from semiotic activities as constitutive of the situation to semiotic activities as facilitating); (ii) the division of labor between linguistic activities and other semiotic activities; (iii) rhetorical mode: the orientation of the text towards field (e.g. informative, didactic, explanatory, explicatory) or tenor (e.g. persuasive, exhortatory, hortatory, polemic); (iv) turn: dialogic or monologic; (v) medium: written or spoken; (vi) channel: phonic or graphic.” (op cit., p. 33-34)

And that leads to semantically subcategorizing the discursive situations.

"So, we will make a basic distinction between activities of 'doing' and of 'meaning', and then further distinctions within 'meaning':

- 'doing': the situation is constituted in some form of social behavior, involving one or more persons. Language or other semiotic systems such as gesture, gaze, and facial expression may be engaged to facilitate the performance of the activity, as when language is used to coordinate a team

- 'meaning': the situation is constituted in some process of meaning. There are seven primary types: 
o 'expounding': expounding knowledge about the world - about general classes of phenomena, categorizing them or explaining them

o 'reporting': reporting particular phenomena, chronicling the flow of events, surveying places, or inventorying entities

$\circ$ 'recreating': recreating any aspect of prototypically human life imaginatively by dramatizing or narrating events

$\circ$ 'sharing': sharing personal experiences and values, prototypically in private

- 'enabling': enabling some course of activity, either enabling the activity by instructing people on how to undertake it or regulating the activity by controlling people's actions

○ 'recommending': recommending some course of activity, either for the sake of the speaker through the promotion of some commodity or for the sake of the addressee through advice

○ 'exploring': exploring societal values and positions, prototypically in the public arena." (op cit., p. 35-36)

In Figure 5.3 already provided, he put down three abstract relations ("being," "doing," "sensing," and here he gives two different ones, "doing," and "meaning." This piling up of different analyses, all seen from the end product "text" in a "stratified" vision does not consider the relations between these strata, or even the hierarchy between them. It leads to the subcategorization of words within discourse. No phylogeny that would imply that each level is in phylogenetic relations with the others just the way consonants and vowels unite to produce roots that are then categorized into spatial and temporal stems, that are in their turn specified in functional values, syntactic functions for the spatial elements and tenses and moods for the temporal elements to produce fronds in both cases. My metaphor root-stemfrond implies a phylogenetic connection from one to the next, and that phylogenetic dimension applies in the emergence of articulated language 300,000 years ago as well as with newborns learning the language or languages of their environment, as well as the production of discourse by the speaking individuals who can always pick a final sentence and turn it into a root and then a stem and then a frond, like in:

$\mathrm{X}$ to Y: All you say is always some sophisticated BS.

Y to X: You may be "sophisticated-BS-ing" me as much as you like, but I will be "blunt-BSing" you in return.

His approach just provides us with socio-semiotic discursive elements (op cit., p. 75).

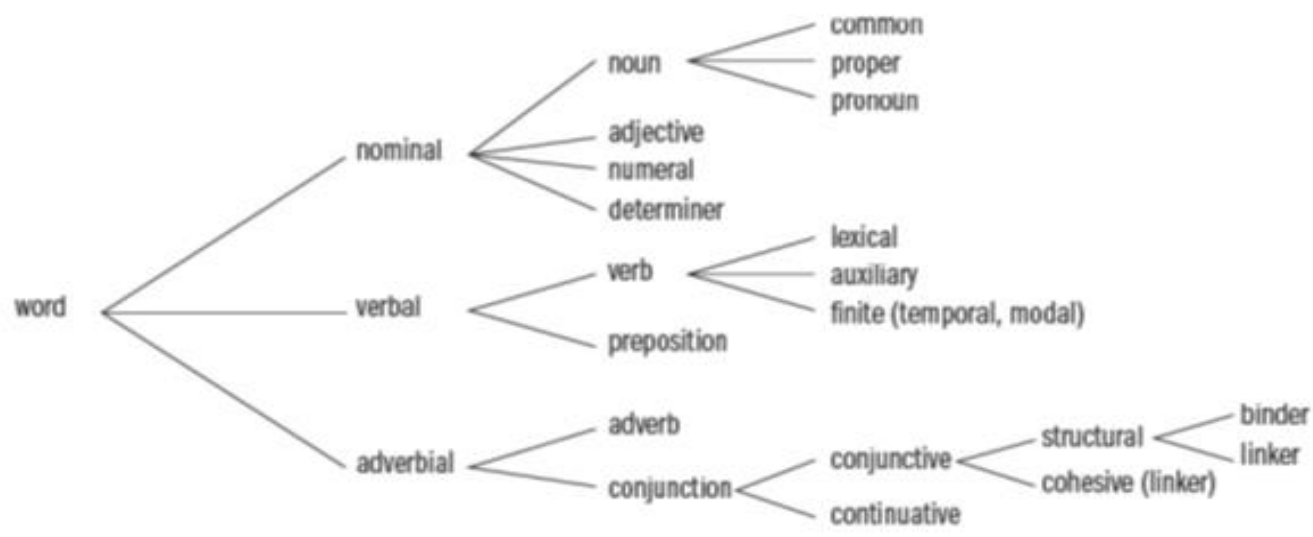

Fig. 2-8 Word classes recognized in a functional grammar of English 
We could of course question the three basic types of words divided in "nominal," "verbal," and "adverbial," not so much in the three categories themselves as in the fact that there is no phylogeny producing these categories and no real architecture linking them together, and first of all what is "nominal" or "verbal" or "adverbial"? No characterization of what is in Indo-European-centered linguistics called a noun to the spatial dimension of human vision and linguistic conceptualization as opposed to the temporal dimension that is behind the "verbal" category that is derived from and thus reduced to an Indo-Europeancentered vision. The third one is problematic since it is some kind of modal intervention of the utterer - or the situation - into the process he/she/they describe and it can be applied to the qualifying or classifying adjuncts of the spatial (nominal) fronds, to the temporal (verbal) fronds, or to the utterance as a whole or the situation that carries this utterance, including the utterer himself/herself/themselves. The absence of these two spatial and temporal dimensions has tremendous consequences, particularly dealing with time from universe-time (which is only the human quantification of universe duration) to operational time (the mental time necessary to produce a text) via inner-process time (a temporal element being seen in various moments of its completion or non-completion) and outer-process time (the connection between the outer-process time and the outside-universe time, generally seen as "tenses" in Indo-European languages). His reduction to past-present-future and his further remark about the reduction of this triple time to double times like past-non-past, present-non-present, future-non-future, etc., make it even more difficult to speak of the temporal dimension of language which becomes exploded by and into the discursive "effets de sens." He does not even reach the level he could have reached with Semitic languages that work on the doubletime-capture in inner-time process: "completed" and "in progress."

This leads him to his basic example "The duke gave my aunt this teapot." He piles up successive analysis of the discursive realizations of the basic notional sentence by moving around the words or the emphasis (theme versus rheme) in the basic structure particularly playing on three concepts of "subject: "psychological subject," "grammatical subject," and "logical subject." The subject of course is discursive hence superficial, circumstantial, and never in the Figures 2.11 to 2.14 (op cit., p. 80-81) that include the passive sentence derived from the original active sentence, can we find the simple structure of the property-transfer verb "give" in a sentence with three nominal actants, thus building an architecture with four elements:

[the duke, Agent and Source] - [gave, Relation: property-transfer] - [my aunt, Goal] - [this teapot, Theme]

I here use Ray Jackendoff's concepts. It is this structure that bars as normal a sentence like "My dog gave my cat US\$100." And yet it is not non-grammatical, as Chomsky would say even if it is non-sensical if we consider it as poetical, or metaphorical, or symbolical.

I will neglect Halliday's further trinity or triad, "textual," "interpersonal," and "experiential":

Table 2-7 Three lines of meaning in the clause

\begin{tabular}{|l|l|l|l|}
\hline Metafunction & Clause as ... & System & Structure \\
\hline textual & message & THEuE & Theme ^ Rheme \\
\hline interpersonal & exchange & woov & $\begin{array}{l}\text { Mood [Subject + Finite] + Residue [Predicator } \\
(+ \text { Complement) (+ Adjunct)] }\end{array}$ \\
\hline experiential & representation & Trussmirr & $\begin{array}{l}\text { process + participant(s) (+ circumstances), e.g. Process } \\
+ \text { Actor + Goal }\end{array}$ \\
\hline
\end{tabular}


We can look as much as we want but there is no psychological dimension, no phylogenetic dimension in the production of a text seen or described by Halliday. And this is obvious when we look for the concept of "mind." You cannot find it. For him, language only takes place in the brain (a common point with Chomsky despite Encyclopedia Britannica). But we all know it does not. At best the brain is the material regulator of the sensorimotor activity of the speaking or writing individual. He seems to totally ignore Bertrand Russell and his lectures delivered in London and Beijing published in $1921^{2}$. The human brain as a brain is similar to that of most mammals, and maybe even all animals that have a brain. The sensors in the body send sensations via the nervous system to the brain that processes these sensations into perceptions and the brain discriminates in these perceptions some patterns it identifies in brain machine code to remember them and recognize them later. Your dog has done all that and it recognizes you, even the sound of your voice on the telephone, and he will show in a way or another that he recognizes you. But Homo Sapiens developed a triplearticulated language from the mutations brought into his physiology and brain to become the long-distance fast bipedal runner he became something like 300,000 years ago. The human brain used its discriminatory capability to join these items in the brain's memory with newly developed words from the rotation of vowels and consonants. And this lexicon enabled Homo Sapiens to experiment on things and words, to speculate on the same with other members of their communities, and eventually to conceptualize these speculations.

In fact, but I am afraid Halliday did not see the humor of one of his formulas, the mind appears in the phrase in bold font in this sentence: "A language is a series of redundancies by which we link our eco-social environment to non-random disturbances in the air (soundwaves). Each step is, of course, masterminded by the brain." (op cit., page 25) In fact, the sensorimotor apparatus of the brain is masterminded by the mind, and the mind came into existence in the brain as a virtual construct because human language also developed as a virtual construct in the mind. The two develop simultaneously and reciprocally. If we understand this essential phylogenetic dimension of the human species, we can then look at the discursive use of language in a totally different way and in a unifying way. Instead of multiplying the functions, we can state only one: the communicational situation, and we can start to build this complex communicational situation, and mind you, one can entertain constant or episodic communicational exchanges with oneself in dreams, in delusions, in simple thinking in silence or aloud for the sole benefit of oneself. That's basically what the Buddhists call meditation, and it can be done in silence or aloud, sitting on a meditating chair, or walking on a meditating track, or lying in a meditating cell. Freud used to say that when he had a mixed couple in front of him, he always considers he is confronted by four people since each individual has a masculine side and a feminine side. It is well known that any well-balanced individual is a triad of people: "me, myself, and I," as a popular saying goes and if we opened up this individual to his environment it would be a quartet: "me, myself, I, and mine."

What I think here is that Halliday proposes a completely scattered array of "effets de sens," hence of discursive final values of texts instead of unifying the communicational situation that has produced Homo Sapiens's articulated language by forcing this

Bertrand Russell, The Analysis of Mind, 1921, London and Beijing,
https://www.gutenberg.org/files/2529/2529-h/2529-h.htm


Pro Edu. International Journal of Educational Sciences No. 5, Year 3/2021

https://peijes.com/ e- ISSN 2668-5825, p-ISSN 2668-5817

communication onto the newborn to simply survive, and onto the Homo Sapiens communities from the very start, partly inherited from anterior Hominins, in order for these communities to survive and expand. See below my graph of the communicational situation in its very complex reciprocal and even symmetrical analysis. We must also state that MAK Halliday got a lot of his inspiration from William Francis Mackey's book, Language Teaching Analysis, 1965.

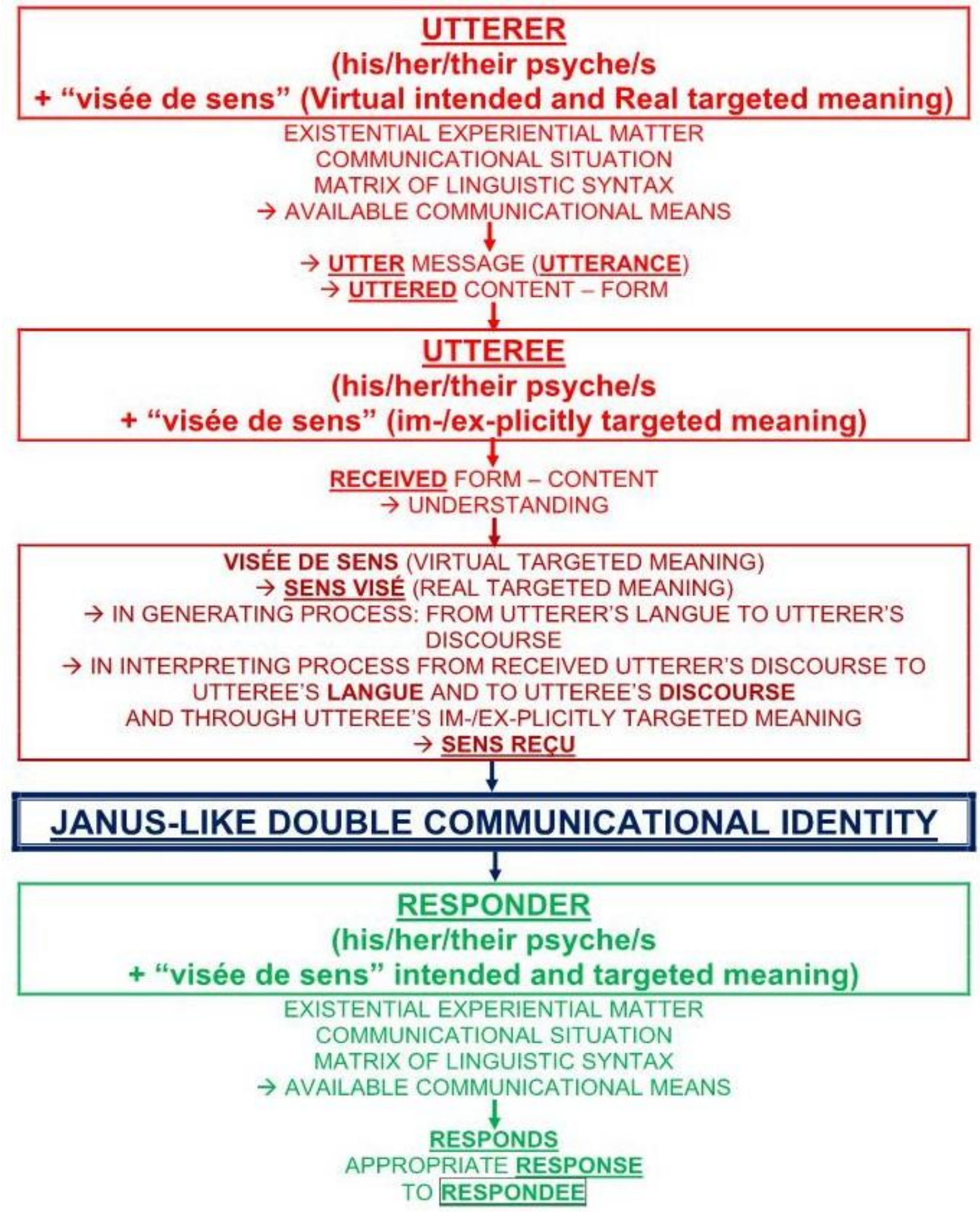


But this notional-functional pedagogy was selected in the early 1970 s by the European Union as $\underline{\boldsymbol{T H E}}$ pedagogy for foreign languages. Under the guidance of Denis Girard, General Inspector of National Education in France, responsible for English, this pedagogy was systematically railroaded into the teaching of English but a lot less in other languages due to some resistance. The result is a total catastrophe, but it is necessary to get into some detail. This is not going to be a full in-depth study of the European policy as for foreign languages. We must keep in mind though the European Union, its Commission in Brussels, or its Parliament in Strasbourg do not decide on the foreign language teaching policy of all the EU countries. It only produces various documents, studies, and suggestions, at times called resources or directives that the various countries in the EU can adopt or adapt to their context. The basic idea is that the EU has defined six levels of proficiency in foreign languages. These levels are used for general studies or reports on foreign-language proficiency in Europe and the various countries of Europe. They are clearly defined as follows in the first chart below.

The ordering of the levels is surprising since it goes against the alphabetical and numerical order of the identification in the second column. It also goes against what many would consider normal, that is to say, a progressing order from weaker to stronger. They chose a "pyramidal" presentation which is anti-alphabetical and anti-numerical. They apply in this classification the same principle used for resumes that are ordered in an antichronological hierarchy. I highlighted in yellow the simple hearing, listening, and understanding specifications of this chart. Behind them, we can see that the first requirement is about understanding what is produced by others (implying native speakers).

Then comes proficiency at producing some information in the concerned foreign language. This chart is a first step in order to understand the policy that is behind it. Proficiency is systematically concerned by the functions the speaker can fulfill with the foreign language. We are in what was called after M.A.K. Halliday a notional-functional approach: The speaker has some notions (semantic meanings) in mind, and he is able to transpose these meanings into a foreign language within a situation that is functionally defined. This chart only contains one, and only one, reference to the professional field, highlighted in green. This chart does not target professional proficiency but some more diffused social or everyday uses of a foreign language. What I said before goes against this minorization of the professional dimension of foreign languages and the strong desire of numerous learners to improve their professional competence and performance with the use of a foreign language and they know very early that they will need foreign languages to enhance their professional skills at all levels of their professional experience. If they don't know this, they should be corrected. 


\begin{tabular}{|c|c|c|}
\hline \multirow{2}{*}{$\begin{array}{l}\text { PROFICIENT } \\
\text { USER }\end{array}$} & $\mathrm{C} 2$ & $\begin{array}{l}\text { Can understand with ease virtually everything heard or read. Can summarise information } \\
\text { from different spoken and written sources, reconstructing arguments and accounts in a } \\
\text { coherent presentation. Can express him/herself spontaneously, very fluently and precisely, } \\
\text { differentiating finer shades of meaning even in more complex situations. }\end{array}$ \\
\hline & $\mathrm{Cl}$ & $\begin{array}{l}\text { Can understand a wide range of demanding, longer texts, and recognise implicit meaning. } \\
\text { Can express him/herself fluently and spontancously without much obvious searching for } \\
\text { expressions. Can use language flexibly and effectively for social, academic and professional } \\
\text { purposes. Can produce clear, well-structured, detailed text on complex subjects, showing } \\
\text { controlled use of organisational patterns, connectors and cohesive devices. }\end{array}$ \\
\hline \multirow{2}{*}{$\begin{array}{l}\text { INDEPENDENT } \\
\text { USER }\end{array}$} & B2 & $\begin{array}{l}\text { Can understand the main ideas of complex text on both concrete and abstract topics, } \\
\text { including technical discussions in his/her field of specialisation. Can interact with a degree of } \\
\text { fluency and spontaneity that makes regular interaction with native speakers quite possible } \\
\text { without strain for either party. Can produce clear, detailed text on a wide range of subjects and } \\
\text { explain a viewpoint on a topical issue giving the advantages and disadvantages of various options. }\end{array}$ \\
\hline & B1 & $\begin{array}{l}\text { Can understand the main points of clear standard input on familiar matters regularly } \\
\text { encountered in work, school, leisure, etc. Can deal with most situations likely to arise whilst } \\
\text { travelling in an area where the language is spoken. Can produce simple connected text on } \\
\text { topics which are familiar or of personal interest. Can describe experiences and events, dreams, } \\
\text { hopes \& ambitions and briefly give reasons and explanations for opinions and plans. }\end{array}$ \\
\hline \multirow{2}{*}{$\begin{array}{l}\text { BASIC } \\
\text { USER }\end{array}$} & $\mathrm{A} 2$ & $\begin{array}{l}\text { Can understand sentences and frequently used expressions related to areas of most } \\
\text { immediate relevance (e.g. very basic personal and family information, shopping, local } \\
\text { geography, employment). Can communicate in simple and routine tasks requiring a simple and } \\
\text { direct exchange of information on familiar and routine matters. Can describe in simple terms } \\
\text { aspects of his/her background, immediate environment and matters in areas of immediate need. }\end{array}$ \\
\hline & Al & $\begin{array}{l}\text { Can understand and use familiar everyday expressions and very basic phrases aimed at the } \\
\text { satisfaction of needs of a concrete type. Can introduce him/herself and others and can ask and } \\
\text { answer questions about personal details such as where he/she lives, people he/she knows and } \\
\text { things he/she has. Can interact in a simple way provided the other person talks slowly and clearly } \\
\text { and is prepared to help. }\end{array}$ \\
\hline
\end{tabular}

The six proficiency levels according to EU descriptions

But the European Union produced another chart in which they cross the six levels, this time in alphabetical and numerical order from left to right with three basic competencies, understanding, speaking, and writing as follows in the second and third charts below. The full chart is available https://rm.coe.int/CoERMPublicCommonSearchServices/DisplayDCTMContent?documentId $=090000168045 \mathrm{bb52}$. These three competencies are further subclassified as "understanding: listening and reading," "speaking: spoken interaction and spoken production," and "writing" as itself. These subclassifications are going from the most superficial to the deepest competence in language reception and production from top to bottom, once again then in logical order from the simplest to the most complex. 


\begin{tabular}{|c|c|c|c|c|}
\hline & & A1 & A2 & B1 \\
\hline \multirow{2}{*}{$\begin{array}{l}\text { U } \\
\mathbf{N} \\
\mathbf{D} \\
\mathbf{E} \\
\mathbf{R} \\
\mathbf{S} \\
\mathrm{T} \\
\mathbf{A} \\
\mathbf{N} \\
\mathbf{D} \\
\mathbf{I} \\
\mathbf{N} \\
\mathbf{G}\end{array}$} & Listening & $\begin{array}{l}\text { I can recognise familiar wond } \\
\text { and very basic phrases } \\
\text { concerning anyself, my family } \\
\text { and inmediate cancrete } \\
\text { survendings wher people speak } \\
\text { sbwly and ckarly. }\end{array}$ & 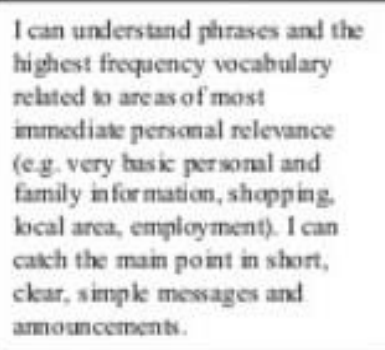 & 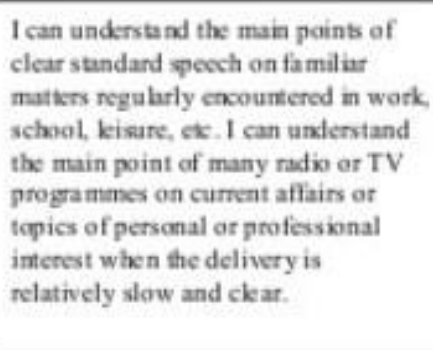 \\
\hline & Reading & $\begin{array}{l}1 \text { can undentand familiar mumes, } \\
\text { wonds and very simple suntences, } \\
\text { for example cu notices and } \\
\text { posters of in catabguss. }\end{array}$ & 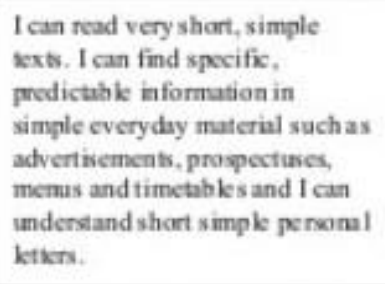 & $\begin{array}{l}\text { I can understand texts that consist } \\
\text { mainly of high frequency everyday or } \\
\text { job-rela ked language. I can undentand } \\
\text { the description of eweats, foelings and } \\
\text { wishes in persomal letters. }\end{array}$ \\
\hline \multirow{2}{*}{$\begin{array}{l}\mathbf{S} \\
\mathbf{P} \\
\mathbf{E} \\
\mathbf{A} \\
\mathbf{K} \\
\mathbf{I} \\
\mathbf{N} \\
\mathrm{G}\end{array}$} & $\begin{array}{l}\text { Spoken } \\
\text { Interaction }\end{array}$ & $\begin{array}{l}\text { I can interact in a single way } \\
\text { provided the other persen is } \\
\text { prepaned so repeat or nephrase } \\
\text { things at a slower rate of spoceh } \\
\text { and help me formulate what I'm } \\
\text { trying to say. I can ask and } \\
\text { answer simple questions in arcas } \\
\text { of immediate need of on very } \\
\text { faniliar bpics. }\end{array}$ & 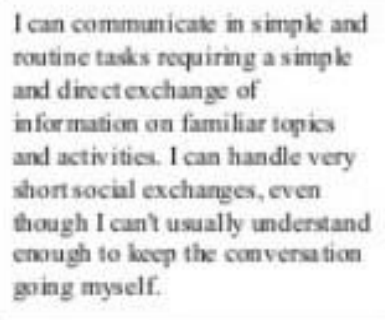 & 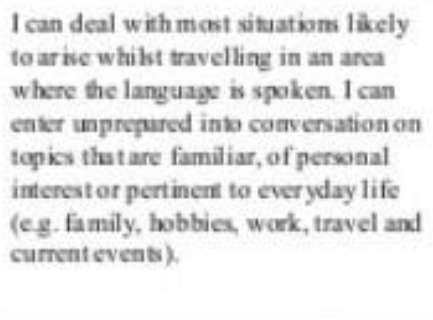 \\
\hline & $\begin{array}{l}\text { Spolven } \\
\text { Production }\end{array}$ & $\begin{array}{l}\text { I can use simple plrases and } \\
\text { senkences no describe where I live } \\
\text { and peopl I know. }\end{array}$ & 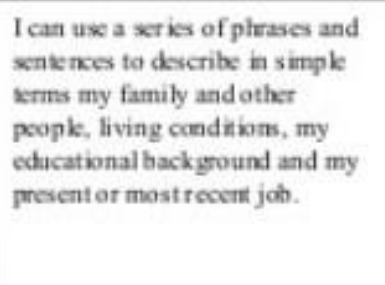 & $\begin{array}{l}\text { I can connect plrases in a simple way } \\
\text { in order to describe expericaces and } \\
\text { events, my dreams, hopes and } \\
\text { ambhitions. I can briefly give reasons } \\
\text { and explametions for opinions and } \\
\text { plans. I can narrate a story or nelate the } \\
\text { plot of a book of film and describe my } \\
\text { reactionx. }\end{array}$ \\
\hline $\begin{array}{l}\text { W } \\
\text { R } \\
\text { I } \\
\text { T } \\
\text { I } \\
\text { N } \\
\text { G }\end{array}$ & Writing & 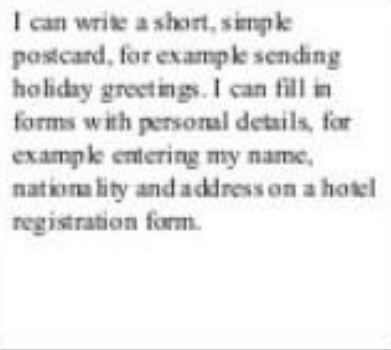 & $\begin{array}{l}\text { I can write short, simple notes } \\
\text { and messages relating oo matkers } \\
\text { in areas of immediate needs. I } \\
\text { can write a very simple pencanal } \\
\text { ktikr, for example thanking } \\
\text { someone for something. }\end{array}$ & $\begin{array}{l}\text { I can write simple comected lext an } \\
\text { topios which are familiar of of } \\
\text { perwonal inierest. I can wrik persanal } \\
\text { letters describing experiences and } \\
\text { impressions. }\end{array}$ \\
\hline
\end{tabular}

\section{European Assessment Grid English 1 (A1-B1)}

A1 and A2 are definitely not for professional use, at best inquiries in a job center to get a job. The professional dimension appears in B1 understanding/listening, but it is immediately reduced to little by the mention "the delivery has to be relatively slow and clear." This is difficult to find in any professional field as soon as there is some stress or pressure in the professional situation. This professional reference disappears in B2. It could be said that most of the competencies listed in B2 could be valid within a professional situation. But it is not specified as such, and it reveals the professional dimension of language competence is not at all dominant in the very process of acquiring the simple or simpler 
competencies within a learning procedure from scratch to fluency. The professional dimension reappears in $\mathrm{C} 1 /$ Understanding/Listening: "I can understand specialized articles and longer technical instructions, even when they do not relate to my field." Then the rest of the $\mathrm{C} 1$ competencies are general. They could apply to the professional field but even when instructions are mentioned it is not specified that in any professional field perfect understanding of instructions is necessary for the civil responsibility or accountability of the worker, and of his employer who must make sure the employee perfectly understands the instructions he receives, lest he becomes a liability in the company he is working for. C2 is even more disquieting for a professional mind because it remains general, and the professional dimension is only mentioned in writing: "I can write summaries and reviews of professional or literary works." And you can see the professional dimension of this writing competence is equalized with literature. Once again, the civil responsibility or accountability of a worker at his workplace is not mentioned though it should be if this teaching foreign languages is targeting professional people who have to deal with foreign countries or move to foreign countries to work. This accountability could lead to some situations that could be considered criminal. Think of the Boeing 737 MAX and it mostly concerned the proper training of the pilots in English which is not the first language of most pilots in the world. The defects or shortcomings in the software and hardware of the plane were not the only liability in the case of the two concerned crashes. 


\begin{tabular}{|c|c|c|c|c|}
\hline $\begin{array}{l}\mathbf{U} \\
\mathbf{N} \\
\mathbf{D} \\
\mathbf{E} \\
\mathbf{R}\end{array}$ & Listening & 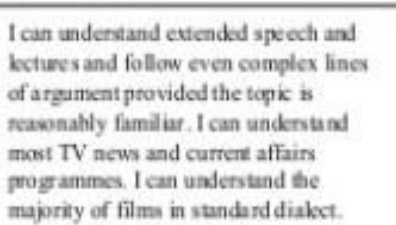 & 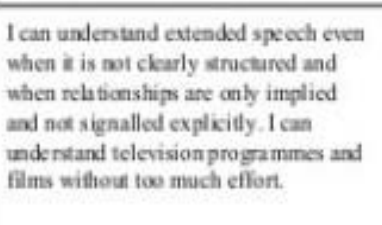 & $\begin{array}{l}1 \text { heve no difficulty in underseanding any } \\
\text { kind of spoken language, whether live or } \\
\text { btoadeas, ever when delivesed at fast } \\
\text { native speed. provided I have sime time } \\
\text { to get familiur with the accent. }\end{array}$ \\
\hline $\begin{array}{l}\mathbf{A} \\
\mathbf{N} \\
\mathbf{D} \\
\mathbf{I} \\
\mathbf{N}\end{array}$ & Reading & $\begin{array}{l}\text { I can read articles and reports conceras } \\
\text { wifh contenporary problens in which } \\
\text { the writen adopt purticular attitades of } \\
\text { viewpoins. I can undenstand } \\
\text { conicmporary lisrary prose. }\end{array}$ & $\begin{array}{l}\text { I can understand bing and complex } \\
\text { factual and likerary teats, appreciating } \\
\text { distinctions of style. I can understand } \\
\text { specialised artic los and bonger technical } \\
\text { insuctions, even when they do wat } \\
\text { relate to my field. }\end{array}$ & $\begin{array}{l}\text { I can read with ease virtally all forms of } \\
\text { the writiva language, iacluding abstract, } \\
\text { strocturally or linguistically camplex kxs } \\
\text { such as manuals, specialised articles and } \\
\text { likeray works. }\end{array}$ \\
\hline $\begin{array}{l}\text { S } \\
\mathbf{P} \\
\mathbf{E} \\
\mathbf{A}\end{array}$ & $\begin{array}{l}\text { Spolen } \\
\text { Interaction }\end{array}$ & 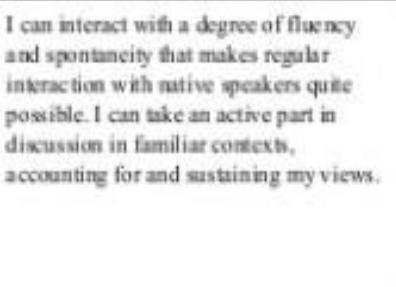 & 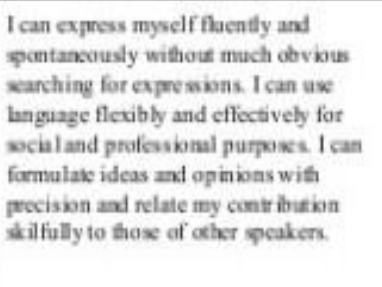 & 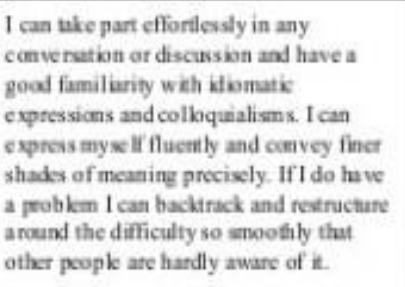 \\
\hline $\begin{array}{l}\text { W } \\
\mathbf{R} \\
\mathbf{I} \\
\mathbf{T} \\
\mathbf{I} \\
\mathbf{N}\end{array}$ & Writing & 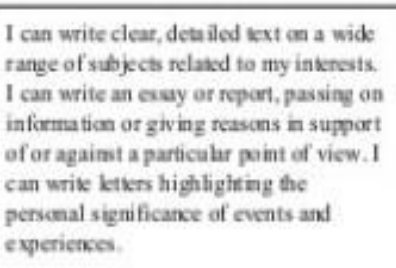 & 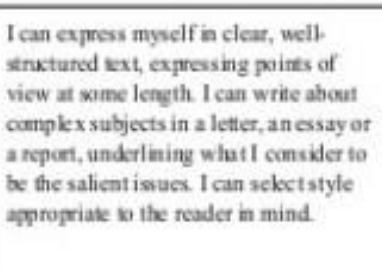 & 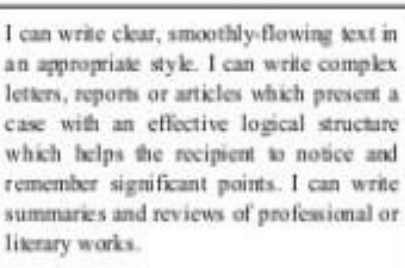 \\
\hline
\end{tabular}

\section{European Assessment Grid English 2 (B2-C2)}

To give a full picture of this notional-functional approach in Brussels, I would like to provide two more charts below giving then the qualitative aspects of spoken language use. The full chart is available at https://www.coe.int/en/web/common-european-frameworkreference-languages/table-3-cefr-3.3-common-reference-levels-qualitative-aspects-of-spokenlanguage-use. We go back to the vertical anti-alphabetical and anti-numerical order, and horizontally five qualities are assessed for each level: range, accuracy, fluency, interaction, coherence. The mention of the professional use of language only appears once in a series of notional-functional elements in C1/Range: "a wide range of general, academic, professional or leisure topics." It is the third, the last but one notional-functional domain. The objections I have already made stand completely here too. The absence of the short-term (college and 
university) and long-term professional objectives and motivations is damaging the motivation of the students since they might be confronted with professional English late in their young life instead of straight away from the start. And what's more, for migrating populations within Europe and from outside Europe, the professional dimension is probably first competing with the social dimension, meaning welfare, health, and social security. It is quite obvious that the "general" and "academic" uses are not very useful in a professional situation or a social urgency situation.

\begin{tabular}{|c|c|c|c|c|c|}
\hline & RANGE & ACCURACY & FLUENCY & INTERACTION & COHERENCE \\
\hline $\mathrm{C} 2$ & $\begin{array}{l}\text { Shows great } \\
\text { flexibility } \\
\text { reformulating ideas } \\
\text { in differing linguistic } \\
\text { forms to convey } \\
\text { finer shades of } \\
\text { meaning precisely, } \\
\text { to give emphasis, to } \\
\text { differentiate and to } \\
\text { eliminate ambiguity } \\
\text { Also has a good } \\
\text { command of } \\
\text { idiomatic } \\
\text { expressions and } \\
\text { colloquialisms }\end{array}$ & $\begin{array}{l}\text { Maintains consistent } \\
\text { grammatical control } \\
\text { of complex language, } \\
\text { even while attention } \\
\text { is otherwise engaged } \\
\text { (e.g. in forward } \\
\text { planning, in } \\
\text { monitoring others' } \\
\text { reactions). }\end{array}$ & $\begin{array}{l}\text { Can express } \\
\text { him/herself } \\
\text { spontaneously at } \\
\text { length with a natural } \\
\text { colloquial flow, } \\
\text { avoiding or } \\
\text { backtracking around } \\
\text { any difficulty so } \\
\text { smoothly that the } \\
\text { interlocutor is hardly } \\
\text { aware of it. }\end{array}$ & $\begin{array}{l}\text { Can interact with ease } \\
\text { and skill, picking up } \\
\text { and using non-verbal } \\
\text { and intonational cues } \\
\text { apparently effortlessly. } \\
\text { Can interweave his/her } \\
\text { contribution into the } \\
\text { joint discourse with } \\
\text { fully natural turntaking, } \\
\text { referencing, allusion } \\
\text { making etc. }\end{array}$ & $\begin{array}{l}\text { Can create } \\
\text { coherent and } \\
\text { cohesive discourse } \\
\text { making full and } \\
\text { appropriate use of a } \\
\text { variety of } \\
\text { organisational } \\
\text { patterns and a wide } \\
\text { range of connectors } \\
\text { and other cohesive } \\
\text { devices. }\end{array}$ \\
\hline C1 & $\begin{array}{l}\text { Has a good } \\
\text { command of a } \\
\text { broad range of } \\
\text { language allowing } \\
\text { him/her to select a } \\
\text { formulation to } \\
\text { express him/ herself } \\
\text { clearly in an } \\
\text { appropriate style on } \\
\text { a wide range of } \\
\text { general, academic, } \\
\text { professional or } \\
\text { leisure topics } \\
\text { without having to } \\
\text { restrict what he/she } \\
\text { wants to say. }\end{array}$ & $\begin{array}{l}\text { Consistently } \\
\text { maintains a high } \\
\text { degree of } \\
\text { grammatical } \\
\text { accuracy; errors are } \\
\text { rare, difficult to spot } \\
\text { and generally } \\
\text { corrected when they } \\
\text { do occur. }\end{array}$ & $\begin{array}{l}\text { Can express } \\
\text { him/herself fluently } \\
\text { and spontaneously, } \\
\text { almost effortlessly. } \\
\text { Only a conceptually } \\
\text { difficult subject can } \\
\text { hinder a natural, } \\
\text { smooth flow of } \\
\text { language. }\end{array}$ & $\begin{array}{l}\text { Can select a suitable } \\
\text { phrase from a readily } \\
\text { available range of } \\
\text { discourse functions to } \\
\text { preface his remarks in } \\
\text { order to get or to keep } \\
\text { the floor and to relate } \\
\text { his/her own } \\
\text { contributions skilfully } \\
\text { to those of other } \\
\text { speakers. }\end{array}$ & $\begin{array}{l}\text { Can produce clear, } \\
\text { smoothly-flowing, } \\
\text { well-structured } \\
\text { speech, showing } \\
\text { controlled use of } \\
\text { organisational } \\
\text { patterns, } \\
\text { connectors and } \\
\text { cohesive devices. }\end{array}$ \\
\hline B2 & $\begin{array}{l}\text { Has a sufficient } \\
\text { range of language } \\
\text { to be able to give } \\
\text { clear descriptions, } \\
\text { express viewpoints } \\
\text { on most general } \\
\text { topics, without much } \\
\text { conspicuous } \\
\text { searching for words, } \\
\text { using some } \\
\text { complex sentence } \\
\text { forms to do so. }\end{array}$ & $\begin{array}{l}\text { Shows a relatively } \\
\text { high degree of } \\
\text { grammatical control. } \\
\text { Does not make errors } \\
\text { which cause } \\
\text { misunderstanding, } \\
\text { and can correct most } \\
\text { of his/her mistakes. }\end{array}$ & $\begin{array}{l}\text { Can produce } \\
\text { stretches of } \\
\text { language with a } \\
\text { fairly even tempo; } \\
\text { although he/she can } \\
\text { be hesitant as he or } \\
\text { she searches for } \\
\text { patterns and } \\
\text { expressions, there } \\
\text { are few noticeably } \\
\text { long pauses. }\end{array}$ & $\begin{array}{l}\text { Can initiate discourse, } \\
\text { take his/her turn when } \\
\text { appropriate and end } \\
\text { conversation when he } \\
\text { / she needs to, though } \\
\text { he/she may not } \\
\text { always do this } \\
\text { elegantly. Can help } \\
\text { the discussion along } \\
\text { on familiar ground } \\
\text { confirming comprehen- } \\
\text { sion, inviting others in, } \\
\text { etc. }\end{array}$ & $\begin{array}{l}\text { Can use a limited } \\
\text { number of cohesive } \\
\text { devices to link } \\
\text { his/her utterances } \\
\text { into clear, coherent } \\
\text { discourse, though } \\
\text { there may be some } \\
\text { "jumpiness" in a } \\
\text { long contribution. }\end{array}$ \\
\hline \multicolumn{6}{|c|}{ Qualitative aspects of spoken language use (C2-C1-B2) } \\
\hline
\end{tabular}




\begin{tabular}{|c|c|c|c|c|c|}
\hline & RANGE & ACCURACY & FLUENCY & INTERACTION & COHERENCE \\
\hline B1 & $\begin{array}{l}\text { Has enough } \\
\text { language to get by, } \\
\text { with sufficient } \\
\text { vocabulary to } \\
\text { express him/herself } \\
\text { with some hesitation } \\
\text { and circum- } \\
\text { locutions on topics } \\
\text { such as family, } \\
\text { hobbies and } \\
\text { interests, work, } \\
\text { travel, and current } \\
\text { events. }\end{array}$ & $\begin{array}{l}\text { Uses reasonably } \\
\text { accurately a } \\
\text { repertoire of } \\
\text { frequently used } \\
\text { "routines" and } \\
\text { patterns associated } \\
\text { with more predictable } \\
\text { situations. }\end{array}$ & $\begin{array}{l}\text { Can keep going } \\
\text { comprehensibly, } \\
\text { even though } \\
\text { pausing for } \\
\text { grammatical and } \\
\text { lexical planning and } \\
\text { repair is very } \\
\text { evident, especially } \\
\text { in longer stretches } \\
\text { of free production. }\end{array}$ & $\begin{array}{l}\text { Can initiate, maintain } \\
\text { and close simple face- } \\
\text { to-face conversation } \\
\text { on topics that are } \\
\text { familiar or of personal } \\
\text { interest. Can repeat } \\
\text { back part of what } \\
\text { someone has said to } \\
\text { confirm mutual } \\
\text { understanding. }\end{array}$ & $\begin{array}{l}\text { Can link a series of } \\
\text { shorter, discrete } \\
\text { simple elements } \\
\text { into a connected, } \\
\text { linear sequence of } \\
\text { points. }\end{array}$ \\
\hline A2 & $\begin{array}{l}\text { Uses basic } \\
\text { sentence patterns } \\
\text { with memorised } \\
\text { phrases, groups of } \\
\text { a few words and } \\
\text { formulae in order to } \\
\text { communicate } \\
\text { limited information } \\
\text { in simple everyday } \\
\text { situations. }\end{array}$ & $\begin{array}{l}\text { Uses some simple } \\
\text { structures correctly, } \\
\text { but still systematically } \\
\text { makes basic } \\
\text { mistakes. }\end{array}$ & $\begin{array}{l}\text { Can make } \\
\text { him/herself } \\
\text { understood in very } \\
\text { short utterances, } \\
\text { even though } \\
\text { pauses, false starts } \\
\text { and reformulation } \\
\text { are very evident. }\end{array}$ & $\begin{array}{l}\text { Can answer questions } \\
\text { and respond to simple } \\
\text { statements. Can } \\
\text { indicate when he/she } \\
\text { is following but is } \\
\text { rarely able to } \\
\text { understand enough to } \\
\text { keep conversation } \\
\text { going of his/her own } \\
\text { accord. }\end{array}$ & $\begin{array}{l}\text { Can link groups of } \\
\text { words with simple } \\
\text { connectors like } \\
\text { "and, "but" and } \\
\text { "because". }\end{array}$ \\
\hline A1 & $\begin{array}{l}\text { Has a very basic } \\
\text { repertoire of words } \\
\text { and simple phrases } \\
\text { related to personal } \\
\text { details and } \\
\text { particular concrete } \\
\text { situations. }\end{array}$ & $\begin{array}{l}\text { Shows only limited } \\
\text { control of a few } \\
\text { simple grammatical } \\
\text { structures and } \\
\text { sentence patterns in } \\
\text { a memorised } \\
\text { repertoire. }\end{array}$ & $\begin{array}{l}\text { Can manage very } \\
\text { short, isolated, } \\
\text { mainly pre- } \\
\text { packaged } \\
\text { utterances, with } \\
\text { much pausing to } \\
\text { search for } \\
\text { expressions, to } \\
\text { articulate less } \\
\text { familiar words, and } \\
\text { to repair } \\
\text { communication. }\end{array}$ & $\begin{array}{l}\text { Can ask and answer } \\
\text { questions about } \\
\text { personal details. Can } \\
\text { interact in a simple } \\
\text { way but } \\
\text { communication is } \\
\text { totally dependent on } \\
\text { repetition, rephrasing } \\
\text { and repair. }\end{array}$ & $\begin{array}{l}\text { Can link words or } \\
\text { groups of words } \\
\text { with very basic } \\
\text { linear connectors } \\
\text { like "and" or "then". }\end{array}$ \\
\hline
\end{tabular}

The results of the teaching of foreign languages in Europe are catastrophic, or at least very disquieting for a policy that has been going on for more than fifty years. It is obvious in the following charts below available at https://ec.europa.eu/eurostat/statisticsexplained/index.php?title=Foreign_language_skills_statistics,

In the first chart, I will not consider all countries but only France. In the 25-64-yearold population from 2007 to 2016 the percentage of people having no foreign language shifted from $41.2 \%$ to $39.9 \%, 4$ percentile points higher than the EU average. In the same population, the proportion of people having one foreign language (all proficiency levels together and with no specification if the first language of immigrants is taken into account) shifted from $35.9 \%$ to $35.4 \%$ which is close to the EU average. The proportion of the same population having two foreign languages (all proficiency levels together and with no specification, if the first language of immigrants is taken into account) shifted from $18.4 \%$ to $20.1 \%$ one percentile point under the EU average in 2011 and 2016. Finally, those having three foreign languages shifted from $4.5 \%$ to $4.6 \%$ and these figures were three percentile points under the EU average, despite the great number of immigrants whose languages could be considered as foreign languages in France. It may reveal most students, and a vast 
proportion of migrants just drop their original languages, at least as for the school system, though I think they are not properly counted since it may reveal ethnicity which is banned from French statistics, and some of them might even pretend they do not speak their original languages at all, or not anymore, to look less foreign.

In the second chart that gives a global vision of France's position in Europe, France is twenty-second out of twenty-eight countries 4 or 5 points under the EU average. Now we have looked at the European situation without any commentary about it, we can shift to France to explain why the situation is so bad for the whole 25-64-year-old population with only $60 \%$ of the people having some knowledge of one, two, or three foreign languages (with the ambiguity that the original languages of migrant populations may not have been counted properly), meaning that $40 \%$ of this population does not have any knowledge of any foreign language. If we speak in education terms, that means languages recognized as possible options in secondary education and the Baccalauréat (high school diploma) and the number of languages is limited by the presence or non-presence of teachers in the various schools.

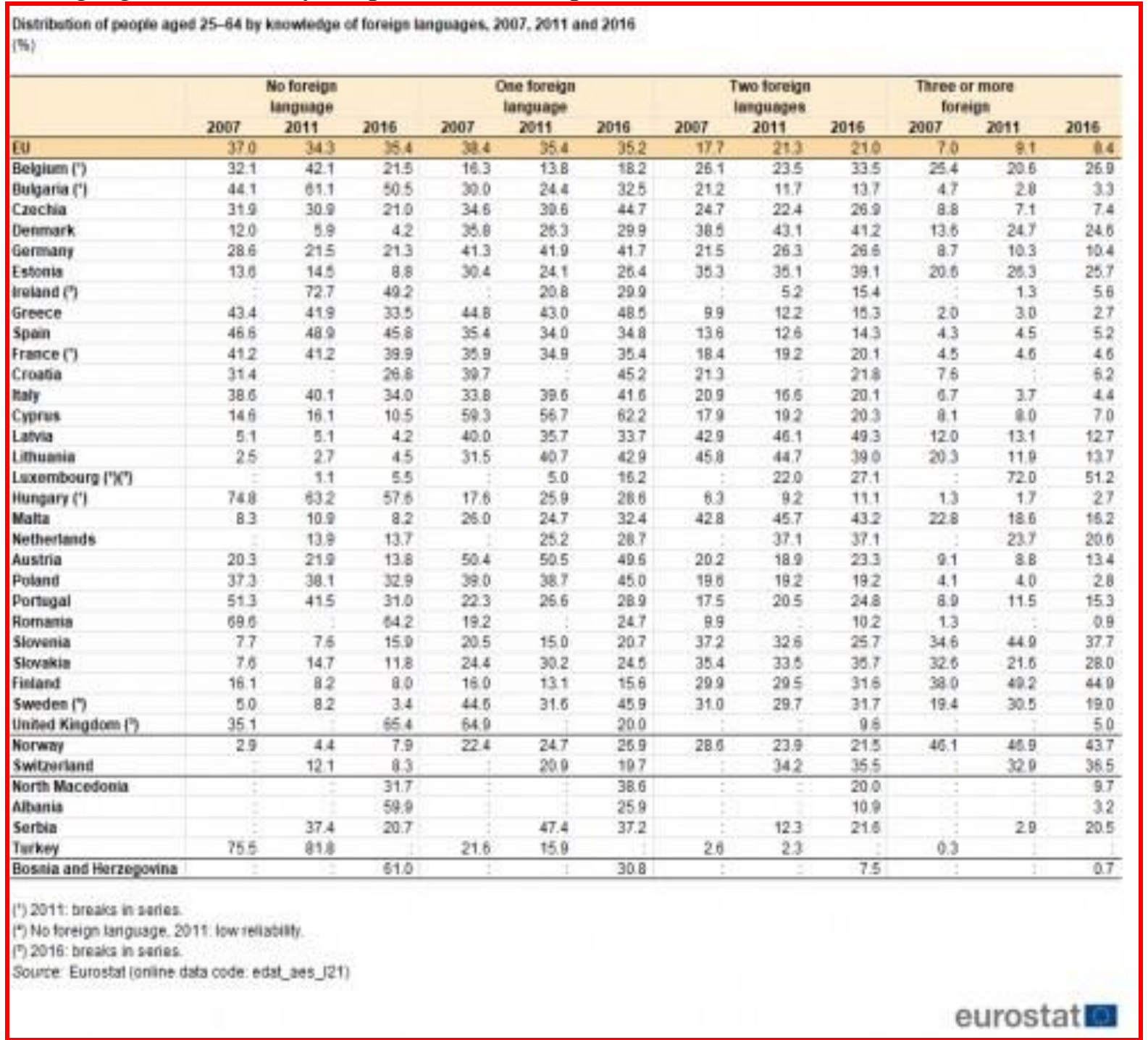




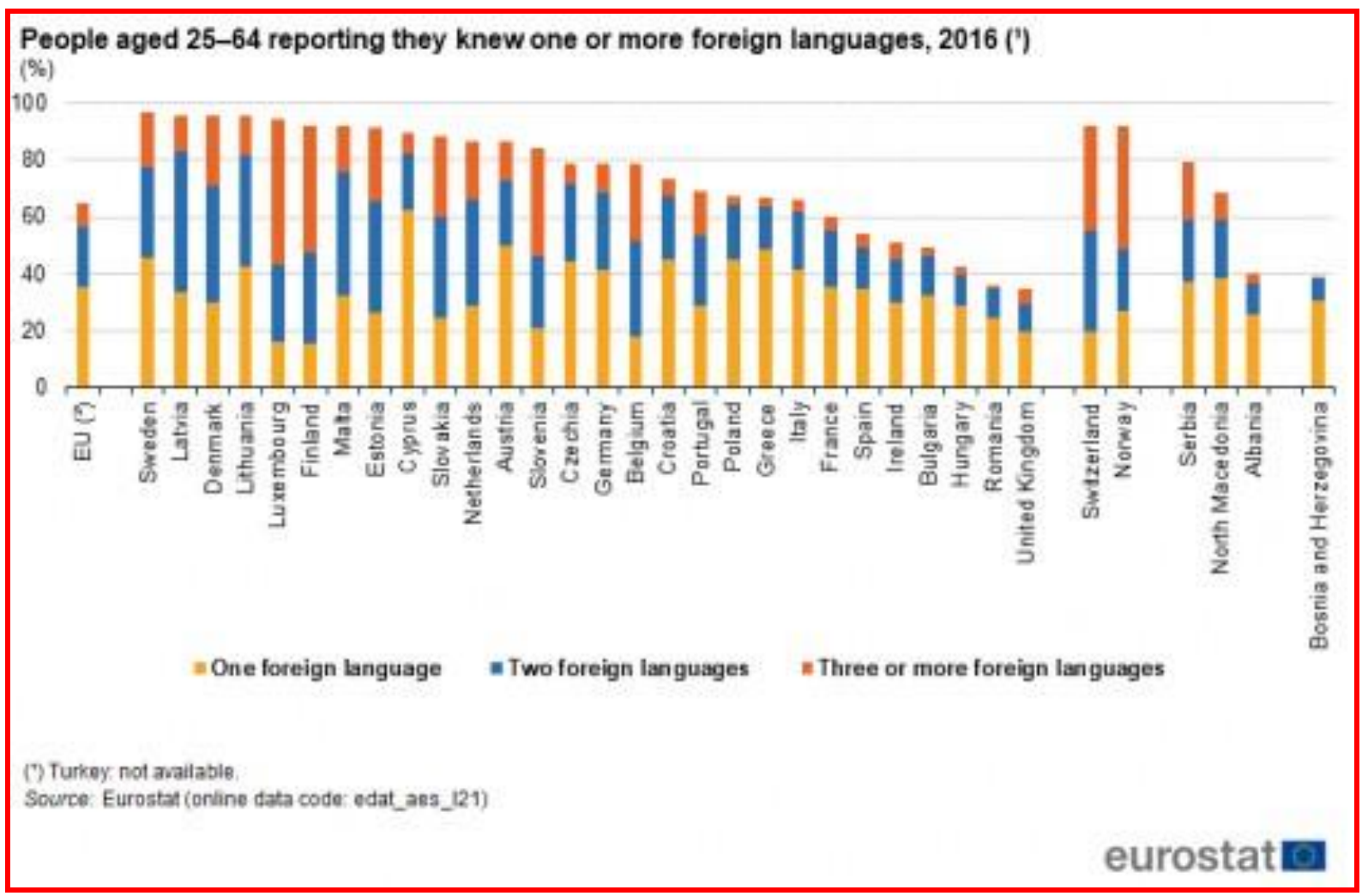

Let's consider the case of Arabic:

The teaching of Arabic in France has been a centuries-old prestigious tradition since the creation of the first chair of Arabic in 1530 by François I. Today, this language and culture are taught in the public service, from primary to secondary schools, but also at the university level, in the Grandes Écoles and the Institutes of Political Studies, a sign of its importance for the future. France is the only Western country that teaches Arabic at all levels with permanent teachers. But our education system is not adapting its offer to the growing demand.

The public teaching of Arabic in 2017-2018 concerns 11,174 students in France and about 2,900 in the DOM-TOM. In addition, there are about 1,000 distance learning students who make up for the shortcomings of the language school map, and nearly 700 students in preparatory classes for the Grandes Écoles, most of whom have a Baccalauréat from an Arab country.

These figures do not correspond to the country's educational needs. In higher education, 5,000 to 6,000 students are enrolled in Arabic degrees, while the number of students taking Arabic for the Baccalauréat is much lower.

The number of Arabic teachers in middle and high schools has fallen from 300 a decade ago to about 200 today. In 2018, there were three positions for the agrégation and four for the Capes in Arabic. As a very first step, these numbers should be doubled. ${ }^{3}$

${ }^{3}$ L'enseignement de l'arabe en France est issu d'une tradition séculaire et prestigieuse, depuis la création de la première chaire d'arabe en 1530 par François Ier. Cette langue-culture est aujourd'hui enseignée dans le service public du primaire aux collèges et lycées, mais aussi à l'université, dans les grandes écoles et les instituts d'études politiques, signe de son importance pour l'avenir. La France est le seul pays occidental à enseigner 
The case is clear, and we are speaking of millions of young people who speak or understand Arabic as their first language.

When we get down to the French level, and France is under the European average as for competence in foreign languages, we get to a direct implementation of the notionalfunctional pedagogy that was advocated by M.A.K. Halliday (1925-2018) for all sorts of migrating people finding themselves in very urgent situations in which they had to master the local languages as fast as possible to simply be able to survive. Denis Girard who imposed this method for the teaching of English in France just forgot some simple elements. Let me list some of these forgotten or overlooked elements.

1- Students in a classroom are confronted with no urgency at all, and all the more so when you go down the grades of any grade school or even kindergarten.

2- The only urgency they may encounter is not within the school situation but within their family situation, their community situation where they may be confronted with more than one language, but quite often for migrant people within Europe or from outside Europe very rarely the local language itself.

3- Even at school the migrant population may encounter some urgency to use their first language or languages to speak with other students or pupils who are from the same migrating culture and language. Note that up to 1971 in Valenciennes, students were punished if they used, in class or in the playground, the local "patois" which was, in fact, the Rouchi dialect of Picard. And punished meant then physical punishment not to mention some possible corporal punishments. Imagine that this spirit is still at work in many minds, and what it can produce at school, in everyday life, in shops and supermarkets, not to mention municipal, regional, or national social services, including post offices or family grant services, not to mention all social security health services. That means some urgency for adults and the parents use their own children as translators when necessary, and this is some kind of urgency for the children if they want to help their parents? But that does not necessarily produce a thankful behavior since it is obviously frustrating linguistic segregation.

4- The French school system is massively understood as having to be Frenchhomogenizing using the French language, French culture, French history, French geography, etc. to achieve this objective. Cohabitation and coexistence are hardly targeted,

l'arabe à tous les niveaux avec des enseignants titulaires. Mais notre système éducatif n'adapte pas son offre à une demande en pleine croissance.

L'enseignement public de l'arabe en 2017-2018 concerne 11174 élèves dans l'Hexagone et 2900 environ dans les DOM-TOM. Il s'y ajoute un millier d'élèves de l'enseignement à distance qui pallie les carences de la carte scolaire des langues, et près de 700 élèves de classes préparatoires aux grandes écoles, majoritairement titulaires d'un baccalauréat en pays arabe.

Ces chiffres ne correspondent pas aux besoins scolaires du pays. Dans l'enseignement supérieur 5000 à 6000 étudiants sont inscrits à des diplômes d'arabe, alors que le nombre d'élèves qui présentent l'arabe au baccalauréat est nettement inférieur.

Le nombre d'enseignants d'arabe dans les collèges et lycées est tombé de 300 il y a une dizaine d'années, à 200 environ aujourd'hui. Il y avait en 2018, trois postes à l'agrégation et quatre au Capes. Il faudrait dans un tout premier temps doubler ces chiffres.

Joseph Dichy, «L'enseignement de l'arabe est issu d'une tradition séculaire et prestigieuse », Le Parisien, 16 septembre 2018, https://www.leparisien.fr/societe/l-enseignement-de-l-arabe-est-issu-d-une-tradition-seculaireet-prestigieuse-16-09-2018-

7890279.php\#: :text=Le\%20nombre\%20d'enseignants\%20d,agr\%C3\%A9gation\%20et\%20quatre\%20au\%20Ca pes. 
not to speak of exchanges and mutual enrichment. Imagine a teacher in middle school asking the students who may object (meaning either Muslim or Arab, since such references are banned, meaning not to be mentioned, or referred to, and certainly not recorded anywhere) to step out of the classroom in the corridor under no surveillance because he, the teacher, intends to show a caricature of the Prophet Mahomet within a class dedicated to the freedom of expression. There are many words for that exclusion ranging from creating distress, to abandoning someone in a distressed situation, and many others, not to mention discrimination.

5- The French school system may say they are employment and vocational minded but the secondary schools that do prepare for employment in industrial and commercial fields only start at sophomore high school level and they are systematically downgraded for promotion among teachers who most of them only target the modern or classical highschools.

6- This last point reveals that secondary education teachers consider their careers have to follow the pyramidal hierarchical academic ladder from middle schools to top classical and modern high schools (characterized by the presence there of the famous prepclasses that drill the top students to go through selective tests and exams to enter all sorts of higher education schools (commercial, engineering, political, and administrative schools). The fact that President Macron closed the most (in-)famous of them in the political arena, ENA (École Nationale d'Administration), just shifts this political selection of future top politicians back to universities where double-major streams in history and political science, or any other first major associated to the second political science major, will prosper, flourish and thrive, and their standard practice is based on selecting the students who had the top results in Baccalauréat, or who had gone through one or two years in some prep-classes for commercial, scientific, or engineering higher education schools. I taught in such a first-year double-major stream in Sorbonne. I tested the students on the first class with the same test as all other first-year higher education classes. The concerned students' scores were 20-25\% higher than average first-year single-major students' scores.

We can now consider some of Denis Girard's ideas. I will concentrate on his last testament-like book, Enseigner les langues: méthodes et pratiques, Bordas, Paris, 1995, six years after his retirement from the General Inspection of the French National Education and three years after his stepping down from most other responsibilities in 1992. The book is interesting but completely marginal about the situation in 2021 in France, though the pedagogy he managed to impose in French for English teaching that survived him for many years and is still active for many teachers of English, is directly responsible for the catastrophe France is experiencing in the teaching of foreign languages, and first of all English. Strangely enough, he rejects most of what he had believed in, at least for some time now and then in his professional life. He rejects linguistics, applied linguistics, and even psycholinguistics and applied psycholinguistics as irrelevant for what he calls the didactics of foreign languages. He rejects generative semantics and Antoine Culioli's (1924-2018) formal enunciation theory. He supported, though he is not mentioned in the bibliography, Henri Adamczewski (1929-2005) and his pragmatic enunciation approach. What's left then in this cemetery of old forsworn good intentions is three things. 
1- the reference to André Martinet (1908-1999) to whom he attributes the idea that "The essential function of this instrument that a language is, is that of communication."4 Immediately associated to Roman Jakobson, and the rather simplistic approach of a communicational situation is as follows in Girard's terms

\begin{tabular}{|c|c|c|c|c|c|}
\hline $\begin{array}{l}\text { In French } \\
\text { EMMETTEUR } \\
\text { ENCODAGE } \rightarrow \\
\text { (Denis Girard, op }\end{array}$ & $\begin{array}{l}\text { INF } \\
\text { CO } \\
\text { age }\end{array}$ & MATION & $\vec{\rightarrow}$ & $\begin{array}{l}\text { RÉ } \\
\text { DÉ }\end{array}$ & $\begin{array}{l}\text { PTEUR } \\
\text { DAGE }\end{array}$ \\
\hline \multicolumn{6}{|c|}{ In English } \\
\hline TRANSMITTER & $\rightarrow$ & INFORN & & $\rightarrow$ & RECEIVER \\
\hline ENCODING & $\rightarrow$ & CODE & & $\rightarrow$ & DECODING \\
\hline
\end{tabular}

Note how the French concept of "émetteur" that states the concerned person is the source of the message is translated in English as "transmitter" which implies this person is only an intermediary for but not the source of the message that comes from another level. That other level is not really envisaged by Denis Girard. But we should go a lot farther and enter applied psycholinguistics or applied psychomechanics that both center the process on the action itself that is an utterance, both the action of uttering and the "message" carried by this uttering.

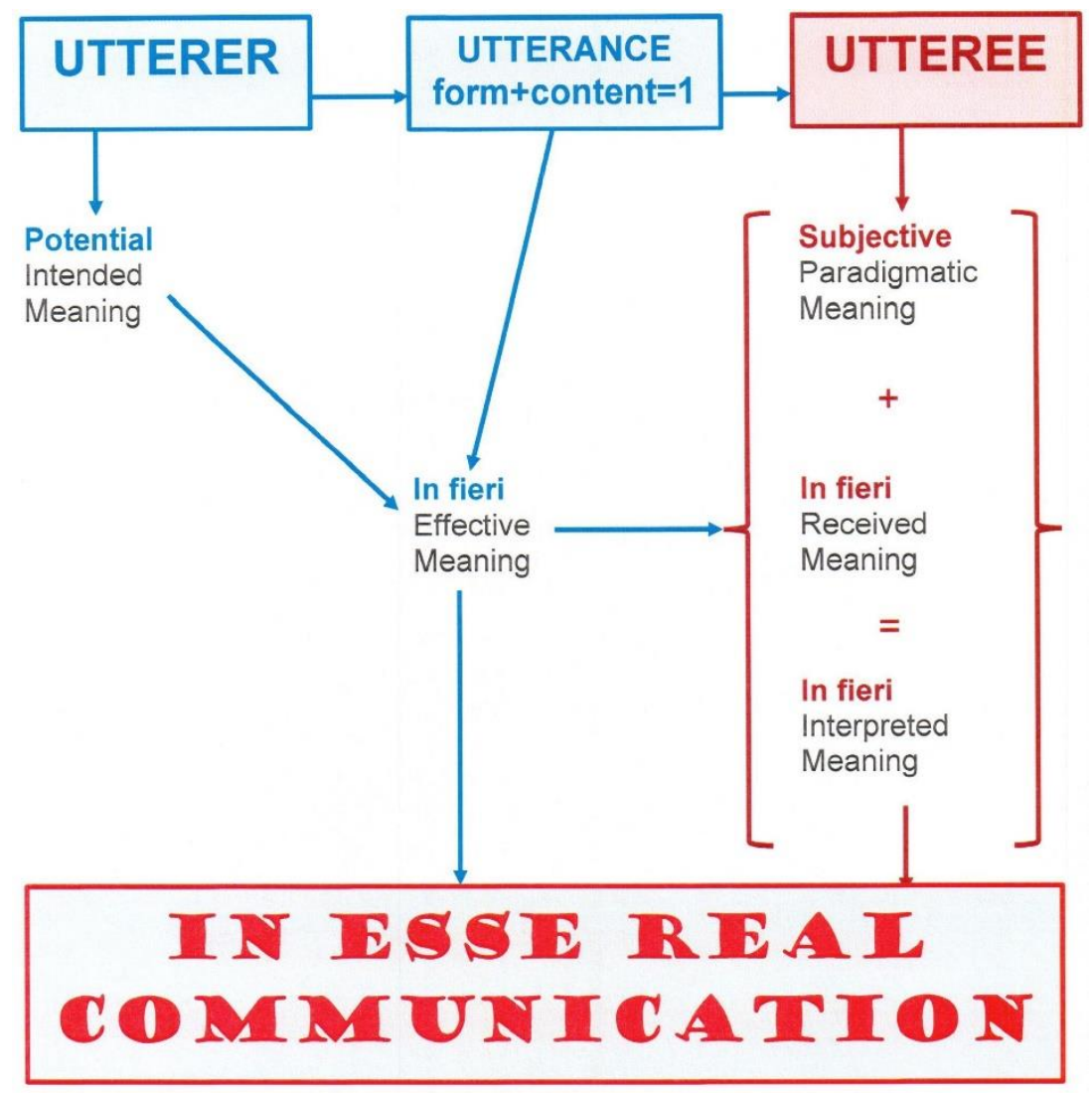

\footnotetext{
4 "La fonction essentielle de cet instrument qu'est une langue est celle de communication." (Éléments de linguistique générale, 1960)
} 
2- That's where we find the second essential idea. Denis Girard is known as the person who adopted the notional-functional approach of the European Commission on foreign language teaching inspired by Michael Halliday, and he was severely criticized for this. here he tries to slightly widen his approach. The main criticism is that the standard class of English is in no way an environment that sets the students in a survival urgency. Denis Girard uses a strange comparison: make the students communicate just the way an old popular saying suggests: "comme on devenait forgeron en forgeant" (the way one became a blacksmith by forging). No student is in such a dire situation in which an apprentice blacksmith has to forge (a complex sequence of actions) to learn the trade, and he has to learn the trade to earn (English is a strange poetic language with this auditory link between "learn" and "earn") a living in a society that was not characterized by the existence of a large middle class and a lot of gentrification. To work in those days was to survive by earning a living to pay for one's food and one's family's food. The ellipse of the comparison implies that any student who does not get a grade over $80 \%$ will have no food till he or she, they anyway, gets or get to this level. So, learning how to communicate cannot be reduced to communicating. (apprendre "à communiquer en communiquant"). Communication is not natural. It is the result of the necessity for a newborn to learn how to attract the attention of their environment to bring a nurturer to them in order to nurture or take care of the nurturee's needs. And we come to that essential triad that Girard states in this final testament of his. Borrowed in this first mention from J. Trim \& al (Systèmes d'apprentissage des langues vivantes par les adultes, Systems for adult learning of modern languages, 1973) and others, on the background of what he calls "the experts of the European Council," the triad is as follows:

"- Communication NEEDS

- Communication FUNCTIONS

- General and specific NOTIONS of semantico-grammatical categories." 5

And you should note the fact that the reference to J. Trim \& al concerns the teaching of foreign languages to adults, hence either to workers of any level in further education for adults precisely, or to migrant adults (and eventually children). In both cases, the urgency of their needs is obvious: to survive, to get a new job, to get a promotion, etc. None of these can be found in a plain primary or secondary classroom, though we could consider the case of vocational secondary education or technical secondary education (all sorts of engineering). The book mentions the first case only once with no in-depth exploration. He considers these to have long-term motivations with no further in-depth exploration and he limits himself to short-term motivation which is found in class work.

But in the book apart from a couple of mentions of this triad without real comprehensive exploration, he always comes back to the artificial situation of the classroom, and he knows about it being artificial but overlooks the handicap.

"In the artificial situation of the foreign language classroom, the "community" speaking that language is more often limited to the teacher alone, possibly assisted by an assistant... Natural communicative situations in the classroom are limited in number... For the most part, [a]

5 "BESOINS de communication - FONCTIONS de communication - NOTIONS générales et spécifiques de catégories sémantico-grammaticales." 
student is placed in simulated communicative situations based on common situations in the outside world." 6

But in fact, and de facto because of his locking himself up onto the classroom and the school including the library, he remains within the artificiality of his starting block:

"Foreign language practice can only be individualized if the emphasis is placed, from the beginning, on a form of 'real communication,' as opposed to 'pseudo-communication,' following the distinction made by Wilga Rivers." ${ }^{7}$

To speak of real communication in a classroom is illusionary. The communication is always fake, pseudo, and prompted by the sole teacher. It is rare - extremely rare, and not envisaged by Denis Girard - that a student may ask a pertinent though also impertinent, meaning provocative, question.

Then Denis Girard ends up aligning series of elements of many natures. "Learn how to communicate with a written: text: 1- careful consideration of the title; 2 - rapid reading; 3more attentive and precise reading. [this last one specified in three bullets]" 8 "Triple objective: 1- communicational; 2- linguistic reflection; 3- cultural." ${ }^{9}$ Group work is specified as follows:

"Documentation plays a capital role in independent work since this one is conceived as the creation of an original document starting from the documentation which will have to be chosen, classified, analyzed. ([Note the three actions] Communication to the class or report of group results: 1- A debate in the form of questions developed by the class... 2- Posting on a board in the classroom... 3- Mimeographing the results of the research... 4- Recording an audiotape... 5- Making an audio-visual montage. [...] Independent work in modern languages should be reserved for good high-school classes." ${ }^{10}$

Of course, today we are in another world with the internet, smartphones (recording videos, taking pictures, recording soundtracks, etc.), phenomenal tools to process any document. But I gave the suggestions about reporting results of group work to show the tremendous hiatus with his conclusion which is selective and rejects foreign language students from primary school to at least sophomore high school classes (from 6 to 16) and think of the modern world that was already coming in 1995 and has nowadays exploded

\footnotetext{
${ }^{6}$ Denis Girard, op cit, p. 48-49, "Dans la situation artificielle de la classe de langue étrangère, "la communauté" parlant cette langue est plus souvent limitée au seul professeur, éventuellement secondé par un assistant...Les situations naturelles de communication dans la classe sont en nombre limité... Pour l'essentiel, [un] élève se trouve placé dans des situations de communication simulées à partir de situations courantes du monde extérieur."

7 "La pratique de la langue étrangère ne peut être individualisée que si l'accent est mis, dès le début, sur une forme de "vraie communication", opposée à la "pseudo-communication", suivant la distinction faite par Wilga Rivers." (Teaching Foreign Language Skills, 1968)

8 “Apprendre à communiquer avec un texte écrit... 1- attention accordée au titre... 2- lecture rapide... 3- lecture plus attentive et plus précise..." (Denis Girard, op cit, p.52-53)

9 “Triple objectif : 1- communicationnel... 2- réflexion sur la langue... 3- culturel..." (Denis Girard, op cit, page56)

${ }_{10}$ "La documentation joue un rôle capital dans le travail indépendant puisque celui-ci est conçue comme création d'un document original à partir d'une documentation qu'il aura fallu choisir, classer, analyser. [remarquez les trois actions] Communication à la classe ou rapport des résultats du travail en groupe. 1- un débat sous forme de questions mises au point par la classe... 2-affichage sur un panneau dans la classe... 3ronéotyper le résultat des recherches... 4- Enregistrer une bande magnétique... 5- Effectuer un montage audiovisuel. [...] Le travail indépendant en langues vivantes soir être réservé aux bonnes classes de $2^{\text {ème }}$ cycle." (Denis Girard, op cit, p. 79-81)
} 
because of the COVID-19 pandemic. He protests against those who say that learning processing is the same for everyone, and he is right in his protest. The point is that he suggests selective procedures dealing with what we have just said about independent group work, and with what he says on bilingual classes with a very strong emphasis on the proper selection of the minority students who will be privileged to have bilingual education. My point is that the best pedagogical action has to be for everyone and not only for the best or most advanced students.

The next stop is the five As: First, Anticipation; second, Apprehension of the text; third, Refinement; fourth Appreciation; fifth, Acceleration. (page 94) The words are transparent except for the third one which is "affinement" in French. And at once on the next page, he reduces them to four by bringing together the second and the third. The text by Laurie Lee that illustrates this quintuple approach is hardly exploited and only on the tenses dealing with the past and the future, and yet for the future, only the verbs used in another tense than the future itself and thus the present tense used to project the subject of the verb into the future. In fact, the three real futures of the text are not even mentioned: "I shall probably stay here for the rest of my life... I still cannot think for myself as a Londoner, nor ever will, nor ever want to... The boys I went to school with..., and they would probably have to give a very long look before they recognized me if $I$ turned there again..." (Denis Girard, op cit, p. 95-96, NB: my highlighting of all verbal modalizations and in red the future forms in the present of the speaker and in the modal past of a hypothesis). In fact, the text would be a lot more pregnant to study the very rich and varied modalization of actions from real to virtual, with all sorts of modals or modalizing verbal constructions. The opposition between the use of "shall" and "will," both in first person singular would require some real explanation to come up with a reason, hence a difference in meaning. A notional-functional approach is not enough. The notion is "future," but the two forms are used in a text that has only one function "declarative personal." Yet the two forms have different meanings that cannot be justified by the function itself. In fact, the use of either form creates two "effets de sens" that are different. Why can this happen? What is so special about "shall" and "will"? We have to get deeper and consider psycholinguistic or psychomechanic facts and dynamics.

But he goes back to the linguistic needs of the students, though it is rather the needs of the lesson by the teacher. Basing himself on the European Council's reflection he comes to six imperatives:

"1- identification of needs.

2- definition of notional-functional objectives.

3- analysis of linguistic contents.

4- elaboration of a methodology and pedagogical materials.

5- pedagogical implementation in the classroom, through various activities favoring interaction.

6- evaluation integrated into the approach and allowing for its inflection." ${ }^{11}$

It is obvious the students or learners have no say in what is happening in the class. The teacher is a puppet master who artificially makes the student-puppets converse in

11 “1- identification des besoins ; 2- définition d'objectifs notionnels-fonctionnels ;3- analyse des contenus linguistiques ; 4- élaboration d'une méthodologie et de matériaux pédagogiques ; 5- mise-en-œuvre pédagogique en classe, à travers diverses activités privilégiant l'interaction ; 6- évaluation intégrée à la démarche et permettant de l'infléchir." Denis Girard, op cit, page 105 
English, but it is the same as in a puppet theater: the puppet master masters the multiple voices of the puppets. In such a prefabricated and predigested pedagogy, only the very good students will be able to remain autonomous and independent. All others will follow if they can, the flow of the master's voice of this puppet show. That always reminds me of the remark of an inspector one day in the early 1990s or so who arrived late of course in my class, and during the question-answer discussion of the document studied on that day, one of the Maghreban students, Moussa with whom I had a complete empathetic relationship, made a mistake in his answer. I only clicked my fingers and Moussa corrected his mistake. The inspector asked me: "How do you do that?" I answer: "It is magic, isn't it?" The secret occurred a few months before when Moussa came to my class one morning (a class with one good third of Maghreban students) unshaved. I was wearing at the time a full and wild beard like some kind of fervent Islamic faithful. I told him in French: "Ts. Ts. Moussa, you don't shave to come to my class? Next time I will bring my "mousse à raser" (shaving foam)." The class laughed, Moussa laughed, and he was my most attentive student ever all year long. Empathy is a lot more than what Denis Girard says later on about psychology (see further on). That leads Denis Girard to his chart page 112 on the place and the role of the program of foreign language teaching elaborated by the General Inspection, hence by Denis Girard himself and his colleagues.

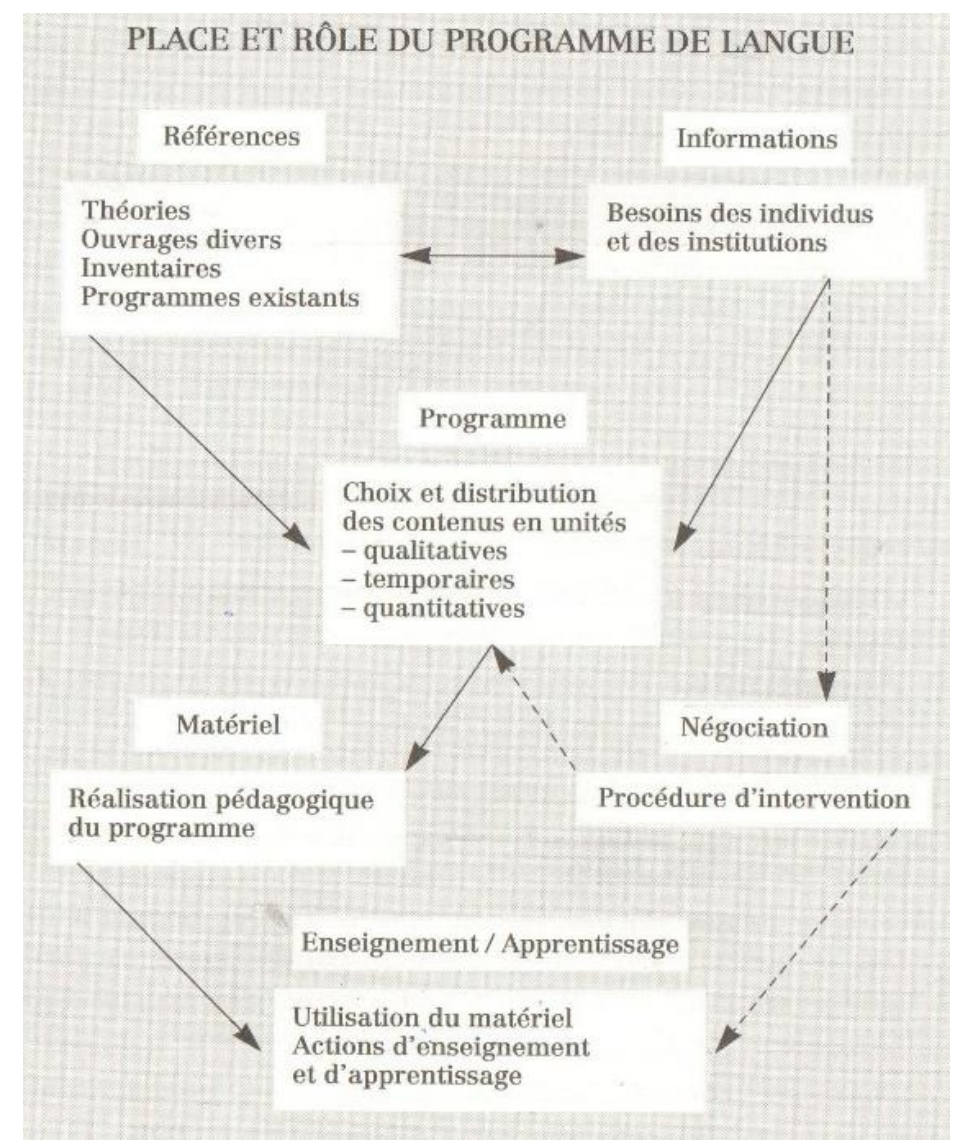

And the program he is alluding to is the national program for all classes in France and part of what is called "official instructions" that come from the top of the hierarchy, hence from Denis Girard for quite some time last century, and you can be fired from your teaching 
job if you dare not abide by them. Where is the student in all that, where are, in these official instructions, the multifarious students who are all different in their needs and abilities, motivations, and achievements as Denis Girard says a couple of times? And sure enough, he comes to the question of the motivation of these students and various (four) factors in the students' motivations:

"1- the socio-linguistic context...

2- the natural aptitude to learn languages...

3- the teaching method...

4- the teacher. And for me, this last one is the most important."12

I will skip the two approaches of what a good English teacher is. Since in the second you just ask the 1,000 students to classify in importance the twenty descriptions you actually provide the students with, the question is, at least leading, and what's more we are never given the said twenty descriptions and we are only given the first ten. That is good old scholastic work. Autonomy is not the real guide of this book, as for the reader. How could the reader be autonomous if he is not given the information, the data? And what's more Denis Girard synthesizes these ten best descriptions in three types of qualities. And the third one is "he must above all be "un bon psychologue"" In other words, he must demonstrate a good level of psychology. But there is absolutely no definition of this quality anywhere in the book, and I must say the French phrase means absolutely nothing because it may mean hundreds of things for the teacher, from demonstrating he/she is a good psychologist to he/she is sympathetic to the students, or even just attentive to the pedagogical difficulties of the students.

We then come to an important point coming from Europe, what he calls the "five methodological themes":

"1- The use of mass media and new technologies (or communication technologies).

2- Bilingual education.

3- Pedagogy of exchanges.

4- Learning how to learn foreign languages.

5- Evaluation of communicational competence." ${ }^{13}$

The first point today has to take into account all distant teaching and learning means revealed by the COVID-19 pandemic. The second point is highly selective for Denis Girard and only concerns a minority of students, hence an elite. The third point is interesting but the possibilities in middle schools and even high schools are very limited and what's more expensive for both the community and the families, this last point meaning it is most of the time socially unequal. I organized an exchange between audio-visual-technology students in Roubaix (college-level BTS) and Bradford three times. It took a tremendous amount of time and on the Roubaix side I was obliged to negotiate a special municipal scholarship for all selected students to be able to take part: two students going on a one-month-and-a-half placement at the National Science and Media Museum, at the time National Museum of Photography, Film, and Television, twice, and the full BTS class (24 students) and the same number of students from Bradford College once. The fourth point goes against the mythical

\footnotetext{
12 1- le contexte sociolinguistique... 2- l'aptitude naturelle à l'apprentissage des langues... la méthode d'enseignement... l'enseignant. C'est pour moi le plus important. » (Denis Girard, op cit, page 114)

13 "1- Utilisation des mass media et des nouvelles technologies (ou technologies de la communication). 2Éducation bilingue. 3- Pédagogie des échanges. 4- Apprendre à apprendre des langues étrangères. 5- Évaluation de la compétence de communication." (Denis Girard, op cit, p. 131-132)
} 
"natural aptitude to learn languages" that Denis Girard endorses. And the fifth point is just a lure since it is only in a real communicational situation that the communicational competence of someone can be assessed. But I would like to come back to the "bilingual objective."

First of all, teaching French and teaching foreign languages in France, not to mention Latin and ancient Greek, are definitely not the same thing if we follow the simplest sociolinguistic approach. Page 147-148 Denis Girard studies the responses of three teachers as for the impact of their linguistic training on their teaching. The first teacher is a teaching assistant ("adjoint d'enseignement") who has taught French for 15 years. Irrelevant if we assume he is teaching French to a French-speaking class. It may have some value if he is teaching French to a mostly foreign-language-speaking class (immigrants) since he might have to use FLE (Français Langue Étrangère, French as a Foreign Language) techniques. But even so, the motivations of learning French for immigrants have nothing to do with learning a foreign language for a French-speaking student. The second person in Denis Girard's approach is a not-yet certified teacher of French in secondary education ("certifié stagiaire") who is teaching French, but in secondary schools, the main objective is cultural and literary. Nothing to do with teaching a foreign language, even if the class has many immigrants. The third person mentioned is a certified teacher of German ("professeur certifié"). This one is valid for our discussion here, but since Denis Girard does not specify the details of the training in linguistics of the said person, we cannot really evaluate the pertinence of any statement from this teacher. But we have to be very precise on the socio-linguistic situation in French schools, knowing that it is "forbidden" to collect any statistics on the ethnic origins of students, and the first language or languages spoken by the students may give a good hint about such ethnic origins. Officially we do not have any statistics on the first language or languages of secondary school students, and as for that, of primary school students.

Let me be clear. Students can be in the following cases and my listing here is not exhaustive.

1- Student whose first language is French, or at least a dialect of French creolized from Breton, Basque, Picard, various Occitan languages, Alsatian and other Germanic languages in the Northeast, and probably some more in the Alps, the Pyrenees, and the Riviera from Italian to Catalan and Savoyard.

2- Students whose first language is not French:

2a- Students whose first language is a European language (special case with agglutinative languages).

$2 \mathrm{~b}$ - Students whose first language is a non-European language.

And each particular language should be taken into account because each language conveys more than simple semantic lexical values (the notions), in fact, a mental frame of thinking, mostly unconscious, and a whole culture mostly conscious. And that's just the point. How can we deal with these cultural elements that are daily present in the reality of each student outside the school? There is only one way to do it and it is to accept that the various cultures find their expression, communication in the classroom, in the class itself, among the students and I am sure that setting groups to study some elements connected to their cultures would be motivating for these students and interesting if not fascinating for the others. And there should be no limits. Denis Girard speaks of "negotiation" in his book. This domain is a field for vast and difficult negotiation for all students to become interested in and tolerant for - the cultures of their classmates. And of course, religions are part of the cultural field. My last payroll-technician class (third-year college level) had students from the 
four corners (even maybe five) of the world and mostly not European, four religions, and many other differences. They had to prepare, from one issue of Time Magazine, a fifteenminute exposé on whatever subject they could find of interest in their particular issues, and they could exchange theirs with those of their classmates. My distribution of one per student plus three or four extras was not an obligation to stay on the one received from me. The class itself was grading the various exposés and their average grading for each student was equal to my own grade which I registered on the spot without telling the class what it was. I got some exposés about the trip of the Pope in Central Africa, some subjects having to do with Muslims in the world, a few on the fate of Black people here and there, mostly in the US and Africa, etc. And there was no real problem in the class.

If we speak of culture, must we discuss the Black Lives Matter movement, or avoid it? Must we speak of the genocidal elimination of Indian culture among Indian children forced to live for years in boarding schools, next to which we are in the process of discovering in Canada and the USA mass graves or "cemeteries" with hundreds of unmarked graves of children? Must we refrain from such subjects in the name of the shock it may represent for some students who are unaware of such realities? Must we do the same as in some states in the USA that are in the process of banning by state-law the subjects of slavery and racism? With my vastly Maghreban classes in industrial engineering studies, I had no problem getting the pros and cons of racism, though an inspector told me one day "There are no arguments in favor of racism." Who is blind? And that's the very point here: Denis Girard never gets down to such questions that are central for our societies and our young people. If you want a discussion in a class, just get them on one of these cultural subjects. Meditate the charts given by Denis Girard where the learner is in the center but completely besieged with all sorts of dominant elements, and institutions, and people, and thus, having very little real initiative or control. ${ }^{14}$

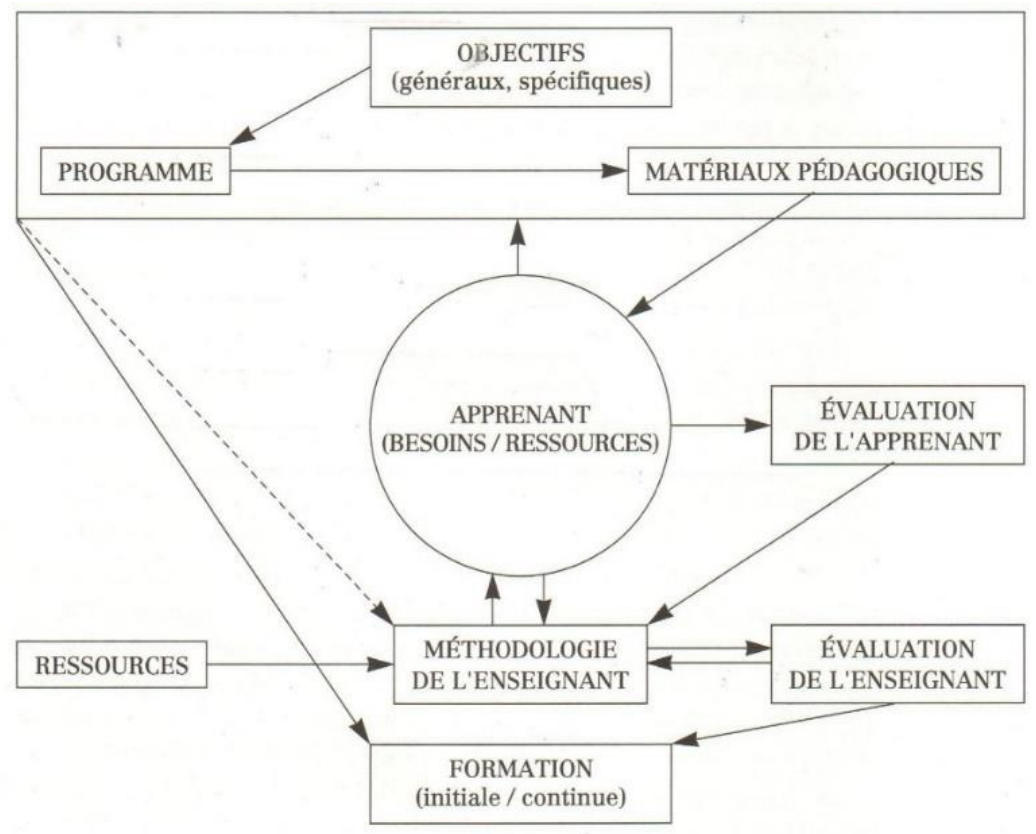

${ }^{14}$ Denis Girard, op cit, page 154. 
To conclude, I will go to Comenius (1592-1670), the same way as Denis Girard does, but for me Comenius has little to tell us because he was working for a society in which an extremely small minority could go into real studies and learn foreign languages, the first one being Latin which was still the lingua franca in Europe in the $17^{\text {th }}$ century. This educated elite became politicians, top military officers, top administrators, top clerical personnel, intellectuals who became university professors for this very elite, etc. Comenius brings up a few interesting ideas but provided we uproot them from their sociocultural context to graft them on our own socio-cultural context. He cannot be a master for our $21^{\text {st }}$ century, especially his project of a perfect language crowning his vision of linguistic reality: Here is Denis Girard's summary of his vision:

"1- to ensure the development of all the languages in the world...

2- to limit this development and diffusion to a limited number of "primary languages"...

3 - choose a single language that would become the language of the international community.

[4-] to invent a new language which is the most perfect in the world... universality... simplicity... efficiency..." 15

Strikingly hierarchical and elitist. And page 168, Denis Girard in his summary of the verbal system of this perfect artificial language says:

"- a single final letter will distinguish the present, the past, the future.

- persons do not have to be distinguished by different endings: a single prefixed letter will suffice." 16

And just 22 lines lower he gives the following example:

"One example will suffice to show in a concrete way the originality and elegance of the universal language imagined by Comenius: the conjugation of the verb 'to be' (BAN) in the three persons of the singular and plural, and in the three tenses only:

$\begin{array}{lll}\text { Present } & \text { Past } & \text { Future } \\ \text { bana } & \text { pabana } & \text { fabana } \\ \text { bane } & \text { pabane } & \text { fabane } \\ \text { bani } & \text { pabani } & \text { fabani } \\ \text { baná } & \text { pabaná } & \text { fabaná } \\ \text { bané } & \text { pabané } & \text { fabané } \\ \text { baní } & \text { pabani } & \text { fabani }\end{array}$

It's definitely simpler than I am, you are, he/she is, we are, you are, they are, etc.!"17

15 " 1 - assurer le développement de toutes les langues du monde...

2- limiter ce développement et cette diffusion à un nombre réduit de "langues principales"...

3- choisir une seule langue qui deviendrait la langue de la communauté internationale.

[4-] inventer une nouvelle langue qui sera la plus parfaite du monde: l'universalité... la simplicité... l'efficacité..." (Denis Girard, op cit, 166-167)

16 “- une seule lettre finale distinguera le présent, le passé, le futur ; - les personnes n'ont pas à être distinguées par des terminaisons différente : une seule lettre préfixée suffira." (Denis Giard, op cit, page 168)

17 "Un seul exemple suffira pour montrer de façon concrète l'originalité et l'élégance de la langue universelle imaginée par Coménius : la conjugaison du verbe être (BAN) aux trois personnes du singulier et du pluriel, et dans les trois seuls temps :

$\begin{array}{lll}\text { Present } & \text { Past } & \text { Future } \\ \text { bana } & \text { pabana } & \text { fabana } \\ \text { bane } & \text { pabane } & \text { fabane } \\ \text { bani } & \text { pabani } & \text { fabani } \\ \text { baná } & \text { pabaná } & \text { fabaná } \\ \text { bané } & \text { pabané } & \text { fabané } \\ \text { bani } & \text { pabani } & \text { fabani }\end{array}$

C'est tout de même plus simple que : je suis, tu es, il/elle est, nous sommes, vous êtes, ils/elles sont, etc.!" 
It is quite obvious that tenses (and time periods) are indicated by the three prefixes $\varnothing$ - pa - ba, highlighted in red by me, and the person, singular and plural, is indicated by the final letters. This is in total contradiction with what he had said before. ${ }^{18}$

We can then move to this $21^{\text {st }}$ century of ours.

\section{4- How can we create urgency for foreign languages in a school environment?}

a- The top best: Virtual Reality.

We are speaking at the global level, and I am just going to outline one possible project. But the necessary software for this project could easily be adapted to other places. I am going to outline a trip of a group of three students to London (and it could be New York, Beijing, or Madrid, with different languages according to the targeted city.

The students (groups of three, mixed - genders, religions, cultures, ethnic origins, etc. - to make things slightly more complicated, meaning human) concerned must prepare their trip to London whose Virtual Reality software could be based on Google's satellite-3D maps. We assume the software exists. What do the three students have to do before getting into VR London? They have to organize their trip from where they are to London, preferably by Eurostar, at least in the last lap of the voyage. They have to look for some accommodation, a bed and breakfast hotel, and there are many in London. They have to make sure they can navigate public transportation, including bicycles for hire, and can get the proper tickets. They need to understand that VR London works like real London, even if it is with virtual monetary means. The program will have a cost to be negotiated within a global project for the identity, image, and various services to be enabled virtually in this VR London. Then the students have to determine the targets of their visit and its length. The software must have the opportunity to be stopped at one moment, and to be saved with what has been done by the

${ }^{18}$ GIRARD (Denis, Julien), Honorary General Inspector of French National Education.

Born on January 28, 1925, in Charleval (Bouches-du-Rhône).

Son of Fernand Girard, Farmer,

and of Mrs., née Marie-Louise Imbert.

Married on January 21, 1950, to Miss Geneviève Bonsergent (4 children: Christian, Isabelle, Pierre-Marie, Jean-Philippe)

Studies : Lycées Mignet in Aix-en-Provence, Thiers in Marseille, Lycée de Toulouse, Literature and Languages Department of Universities of Toulouse and Paris, Ecole Normale Supérieure in Saint-Cloud.

Diplomas: Agrégé (top qualification degree for teaching) of the University

Career: Agrégé teacher of English at the Secondary schools of Beauvais, Fontainebleau and then at the Elsatian school in Paris (1951-1956), Cultural Attaché to the French Embassy in London (1956-1960), Principal Inspector of English in Morocco (1960-1963), Deputy Director and then Director of the Agency for the Study and Coordination of French Teaching in the World (1963-1967), Regional Pedagogical Inspector of Paris Academy (Administrative managing authority in one French departmental territorial unit,1967-1976), Inspector General of National Education (1976-89), Honorary President of the National Association of Regional Pedagogical Inspectors, Member of the French Association of Applied Linguistics and the Linguistic Society of Paris, President of the Modern Languages Group of the Council of Europe (1985-92), Honorary President of the International Association of Teachers of English (IATEFL) (1989-92).

Works: Poems by Jacques Prévert (1961), Cassell's New French Dictionary (in coll., 1961), Co-director of the collections Passport to English and It's up to you, Pédagogie de l'anglais (collective, 1972), Applied Linguistics and Language Didactics (1972), Modern Languages (1974), Grammaire raisonnée de l'anglais (1978), Dictionnaire de l'anglais d'aujourd'hui (collective, 1982), Guide de l'anglais précoce (in coll., 1992), Dictionnaire de poche-anglais (in coll., 1994), Enseigner les langues: méthodes et Pratiques (1995).

Awards: Officer of the Legion of Honor, Knight of the National Order of Merit, Commander of the Academic Palms, Volunteer Resistance Combatant Medal 
three students so that they can come back later on and get started again where they had stopped in the previous session.

The students have thus determined what they want to visit and do in London. They will only be able to visit places that have a Virtual-Visit program. The students must make sure it is the case with the places they want to visit. They must make sure these Virtual Visits have an AI-guide that/who can answer questions and take the students to some of the things they want to see. The students must make sure their budget is clear so that they can be credited with the virtual money they will need. All that has to be done in English. Even in France, Google Chrome is able to speak English, and a blocked option for pedagogical uses has to be developed if it does not exist yet. The students have to prepare their trip's program in writ with as much information as possible and in English of course. They can include a restaurant or a theater show if some restaurants and theaters could provide a virtual dinner or lunch, or a show. Why not an opera if Covent Garden and the English National Opera have such virtual programs. Same thing with the National Theatre (https://www.nationaltheatre.org.uk/shows/paradise, still a long way to go) if it has a virtual program of the type. If not, it is high time the project is developed. And you can also think of the Tower of London, Westminster Abbey, the Palace of Westminster, Buckingham Palace, the National Gallery, the Albert Hall, the Tate Britain, the Tate Images, and the Tate Modern, Madame Tussaud's, etc., who should enter such a global program: allow everyone in the world to visit your collections, your shows, and whatever you can offer to a vast international public. Note in this project, the virtual visits will have to be exclusively in English.

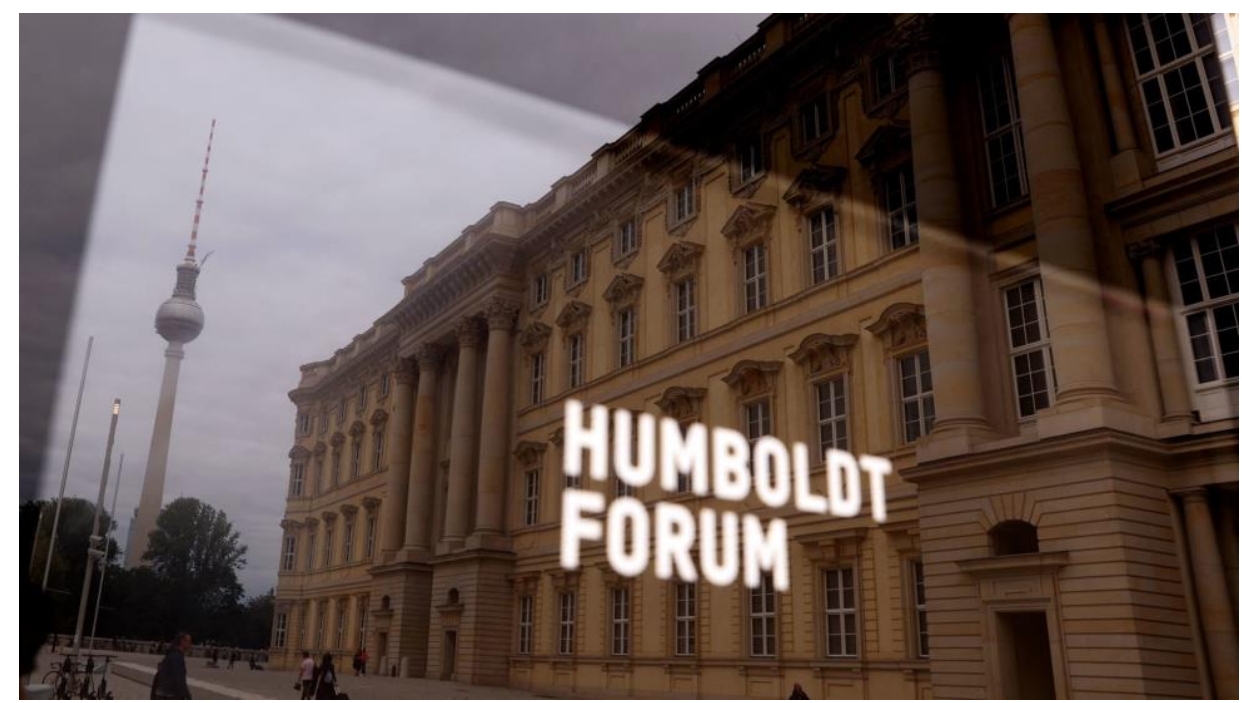

The finally rebuilt Palace of Berlin with the TV tower, built by the GDR, in the background (https://www.humboldtforum.org/en/visit/virtual-visit/)

I am not dreaming. Some of these institutions have to have such virtual visits since they want and should compete with Le Louvre in Paris that has a virtual visit available (Enjoy the Louvre at home, https://www.louvre.fr/en/online-tours). For theaters it is rather simple to work on a virtual show that was recorded live and, in whose house, a certain number of seats can be reserved to the virtual visitors, for example, no more than three, four, or five. Since it is virtual the show can be played thousands of times simultaneously with three, four, or five real visitors sitting in the front row or in very good seats. Check the brand-new museum in 
Berlin, the Humboldt Forum and you will have a glimpse at tomorrow's world, sorry at today's post-pandemic world.

Such a project requires very good software with a very large database in the cloud so that the real visitors of this virtual reality setting can download the program they want in realtime with the possibility to stop when necessary and to go back to this very same point to go on with the program. We are speaking of $5 \mathrm{G}$ here and we must remember that the Chinese are already experimenting in real situations the next generation they call very conventionally $6 \mathrm{G}$.

That's the answer to Girard and the European Union's notional-functional tradition. Here you can have real communicational opportunities in a virtual-real environment. The communicational situation is real in its very virtuality. From people who have tested such products, I heard that the situation is so real that the body may react in a simple way: vertigo, VR-sickness comparable to airsickness, seasickness, carsickness, bus-sickness, etc. That's what we must target. What's more, the teacher can go along, or at least a virtual avatar that could be absolutely realistic and true-to-life, so that the teacher could be in twenty VR visits of London at the same time.

The only problem I can see is the question of the protection of the personal data of the students, or the teacher, the protection of their privacy. But that can be solved even if we are far from being able to guarantee the full security and protection of personal data and privacy. Another problem is the fact the visitors have to behave like normal real people. There is a fascination with such virtual situations for some individuals to forget they are human, and they have to respect some codes of behavior, language, and human decency (all meanings possible for this word). Of course, the students will not be really in this environment. Only their own "real" avatars under their "real" names will be in VR London, but the real students, and the teacher, have to keep their avatars under control. That's a real problem. Just as a foreign-language student who was diagnosed with dyslexia at the age of five or six, who went through a correcting routine to solve the problem in his first language, and has been declared "healed," sees his dyslexia coming back when he starts learning a foreign language, the bestbehaved person in real life can see his/her real avatar (himself or herself) behave as if he/she had lost this educated behavior of his or hers. A student of mine who is 28 , was diagnosed dyslexic at the age of 8 and duly treated for it and declared healed in French. Today at his advanced age, he demonstrates, in both oral and written expression, signs of survived dystemporal and dys-local mistakes like mixing up systematically "before" and "after," "behind" and "in front of," etc. We have to keep in mind in Virtual Reality that what has been repressed (or "healed") deep in one's unconscious or subconscious, at times many years ago, may, and I will even say will come out in a VR situation. All the more so with children and teenagers.

That's where Girard's "un bon psychologue" (meaning "being a benevolent and responsive person") is slightly short. It takes good preparation for psychological crisis situations and a tremendous empathetic power to cope with such crisis situations. My experience is physical contact might be the necessary response, but what physical contact? And it is a good solution. In Mende, France, one night in a nightclub with some of my students, I noticed a couple was going through some disturbing circumstances. I went out and the young woman followed me, and I had to lend her a shoulder and a hug for her crying. Her young partner (or boyfriend, though he was not a boy anymore) came out shortly after, and 
the two of them found the proper terms for reconciliation. Any teacher with some empathy has been through such situations. Teachers have to be prepared for it, even trained for it.

\section{b- Chatbot and Artificial Intelligence.}

This pair or couple of computer science inventions, the chatbot and artificial intelligence could transform our teaching practices. This time there is no important investment necessary to set up the action; Each school would have to have a special computer room where the machines are dedicated to hosting a chatbot, hence is a chatroom to which each student, individual or in pairs could get connected and meet a chatbot with an Artificial Intelligence. This chatbot should be able to entertain a conversation with the students, in foreign languages of course, on topics chosen by the students. "Today let's speak about Queen Elizabeth $1^{\text {st }}$." The chatbot should have at his disposal a vast database on the topic and thus be able to entertain the students, answer their questions, and ask them some questions. The students should have in front of them a tablet or a portable computer that could enable them to search the Internet at the same type, hence a pair would be better than a single student so that they could share the search on one side and the chatbot on the other side. The chatbot should accept being interrupted with a question, some criticism, or even some refusal of an argument or a fact. Such chatbots are used on smartphones by companies providing medical patients with long chronic diseases with daily contact and discussions about their diseases and the chatbots may make decisions about contacting the medical service dealing with the patient, a nurse, a doctor, and even set up an emergency procedure if it (the chatbot) deems it necessary. I am told by a student working in such a company that some strange but foreseeable reactions from the patient can occur. The chatbot is only a chatbot and it is limited to one particular disease concerning one particular patient. Yet the patient, apparently more frequently when young, tries to engage in a personal conversation with the chatbot who is not prepared for it. And we would think it should.

Here we are dealing with teaching and learning English. For teenagers, the game is a game and as such fascinating and captivating, in one word habit-forming if not addictive. Teenagers are able to enter such situations as if they were real. If on the subject requested by the students (a pair of students) the chatbot has a good database behind its robotic face, and this face can be perfectly human since it is nothing but an avatar, and the students should be able to change the look of this avatar if they prefer a man or a woman, why not Elizabeth $1^{\text {st }}$ herself, then the conversation becomes real. The communicational situation is real even if it is between two students and a robot. We must understand that such a chatbot is valid for the whole world, for all students in the world who want to learn English and have a real conversation in English with such a chatbot. The investment is thus extremely profitable, even in the short term because of its possible use by millions of people. It could even be made available to independent private people who would like to have such a learning and teaching conversation. It could be sold as a pedagogical game like any other game, and we know the game industry is immensely profitable. The real problem, if we consider it as a game, is that it has to have a surrounding environment, like a withdrawing room in Windsor Castle or any other stable room or space, with the possibility to inject from-time-to-time images from the database connected to the subject and what is being said. It could easily include excerpts from Shakespeare's, or Marlowe's, or Ben Jonson's plays actually produced in the reconstructed Globe theater in London. Think of the parallel between Queen Elizabeth $1^{\text {st }}$ and Lady Macbeth, with an obvious rhyming ending, even if according to normal 
versification rules in English it is a mediocre rhyme since the initial consonant of the rhyming syllable "-beth" is the same in the two names. It should have been "-meth" or "peth" or any other rotating initial consonant. Including Ø, "fifti-Øeth."

\section{c- Telephone, Smartphone, and videoconference.}

I vastly used this technique in the 1990s for further education in a school or a company. In the first case, the school was providing me with two connected telephones on the inner telephone network (hence at no cost), one for me and one for the student. The two telephones were in two rooms so that it was real. The student could not see the teacher. In a company, the student had received on Wednesday a short technical document and I called him, from my school at his workplace, at his workstation on a set day at a set time. He had fifteen minutes to explain what the document was about and answer my questions. When I started this with a class of twenty further education students inside their company, they hesitated. But after two or three volunteers, they understood the great value of this one-onone at their workstation. Their colleagues respected them, maybe even admired them because it takes courage to have a fifteen-minute telephone call in English with an invisible entity, the teacher who is both invisible and unheard by the audience of the student's colleagues. At the time the telephone calls were paid by the school as pedagogical expenses. Today we have smartphones, and these smartphones provide us with total freedom as for the length of calls since the subscription is generally a flat rate for such calls and texts. The smartphone can even provide the callers with the picture of the persons concerned if the camera is on with Skype for example. Such calls can be with Microsoft Team or Google Meet or Zoom and it is visual as well as audio. But I favor the blind telephone because of the psychological effect of this blindness. The caller has to completely let him/herself go into the call with no help from any image. This requires concentration and this concentration is good for the English received and produced in such conditions.

I vastly practice this blind telephone or Microsoft Team calls for full one-hour sessions with adult further education. It is very interesting and effective. Note it is possible to record the sessions so that the student can listen to them again and pick the various mistakes he/she made. The teacher could do the same in order to grade the said recording. The live conversation can be graded as for reactivity, the creativity of answers or responses, tone and clarity, etc. Further work on the recordings could concentrate on the sole linguistic qualities or mistakes of the student's performance in English.

\section{d- Balancing act.}

That is where things become both tricky and absolutely mesmerizing. Imagine the VR visit to London, and imagine the teacher from his office at the school calling the students who are in the Virtual Reality visit of London and asking them questions about what they had done, what they are doing, how the people around them are, friendly or not, etc. That means the students or rather their real avatars in the VR visit have their cellphones or smartphones in their pockets, available and open to calls. That's adding telephone communication to VRvisit. It multiplies exponentially the depth and involvement of the students' participation in the experiment that becomes an experience.

Then the students can be requested to present a summary of their experience to the whole class, those who have had a similar experience and those who still haven't had such an experience. Imagine the questions. That is a real, in no way virtual, communicational 
situation. We are here dealing with a completely new way of looking at teaching or learning a foreign language. The teacher is a new being in this situation. The teacher is a guide, is an empathetic character in reality and Virtual Reality, able to lend his shoulder or hand to those who need it, to encourage or reward or pacify those students according to their needs from "being pushed" a little bit, to "being refrained" a little bit, to "finding solace" or "encouragement" or "understanding and ethical guidance."

"Understanding" is the first and foremost quality of the teacher of today and tomorrow: to understand the emotions, the difficulties, the requests, the enthusiasm, the daring desires of the students. That requires a lot of "empathy." But it also requires some "ethical awareness." The teacher may think he is a new-era guru for the students. That would be a mistake. The teacher is a new-era ethical guide who keeps the student within ethical limits that are not supposed to be seen or felt as restrictions, alienation, or even obligations, but as deep cultural human power. I do not use the word "humane" which implies the "humane person" is superior to the people he/she is humane with. We are speaking of humans, equal humans, humans who are supposed to deal with one another on absolutely equal terms. And that implies all elements that could lead to some kind of differentiation (positive) or segregation (negative), such as sex, gender, race, ethnic origin, national origin, religion, etc. This ethical guidance also implies that the students, as well as the teachers, are modest in all the possible meanings of this word in English, as Merriam-Webster defines it:

Modest, adjective

1a: placing a moderate estimate on one's abilities or worth

1b: neither bold nor self-assertive: tending toward diffidence

2: arising from or characteristic of a modest nature

3: observing the proprieties of dress and behavior: DECENT

4a: limited in size, amount, or scope, a family of modest means

4b: UNPRETENTIOUS, a modest home.

We have to understand that in this perspective all available means are to be used: all the machines I have spoken of, plus all the software I have alluded to. But also, all Artificial intelligence available and the databases they need in order to be what they are supposed to be, encyclopedic resource centers at the tip of the fingers of the students, the teacher, and the AI chatbot. It also requires the use of facial recognition cameras and software to know "who is who," "where is who," "when is who," and what "feelings" or "emotions" this who is going through. Body and facial language are often speaking volumes that cannot be captured in simple words. Such VR experiments and experiences bring up in the students - and the teacher - impulses, feelings, emotions, desires, all of them, negative as well as positive, that have often been buried in the unconscious or subconscious. The BBC series "Waking the Dead" is essentially based on such levels of human personalities and people considered as normal, friendly, and even amorous, who are revealed to host monsters in their deeper layers. The best example is Jack the Ripper who was never identified because in normal life he probably was a person, a man who was normal, banal, respected, etc. Confront such a person to a VR experience and experiment, and the monster will come out.

\section{e- Executive Summary.}

All along we have to understand that the learners have to be encouraged to speak of what they like or dislike or whatever, and the teacher must be able to follow and respond to the provocation or the frustration and inhibitions of the students. That's where the class unit is 
important. Regularly, there should be one teacher-class session where the students report on what they have done, have learned, have missed, have not understood in the freest possible confrontation that has to remain civil of course. We are speaking of each pair or trio confronting their own experiences and lessons learned to all the other pairs or trios who will do the same in due course. Confrontation, discussion, and improvement.

There is a question of age: under 16 or 18 , there might be some limitations to respect, or the students have to learn how to deal with these beyond-limits subjects or attitudes with which they may be confronted. If London is inhabited in the VR-version of it, with normal people, all of them being avatars of real people somewhere, these inhabitants might confront the visitors with aggressive or even alluring and inviting attitudes. We often think we have to teach girls how to defend themselves against enterprising or tantalizing individuals generally defined as men. We forget first these enterprising and tantalizing people may be women, and we also forget that boys can be the targets of the same type of people, be they, women or men. Before releasing students in such a VR experience, we do have to make sure they can cope with such situations. And that's where the smartphones in the pockets of each student in the experiment have to remain active to eventually prevent some dire consequences. The role of the teacher then is a lot more complicated. We must keep in mind the students are accountable for what they do in this Virtual Reality universe they are visiting, and the teacher is accountable for the harm that may fall upon the students, even if this harm is only psychological or mental since we are in a Virtual Reality universe.

\section{5- Beyond the pandemic: PRELIMINARY CONCLUSION}

The mistake to go back to what IT (whatever "it" is) was before is just a mistake. We are neglecting the psychological, mental, and social consequences of the pandemic and the confinements onto the people. We must understand for example that many hundred thousand children of any age have become orphans when their parents were taken away by the pandemic.

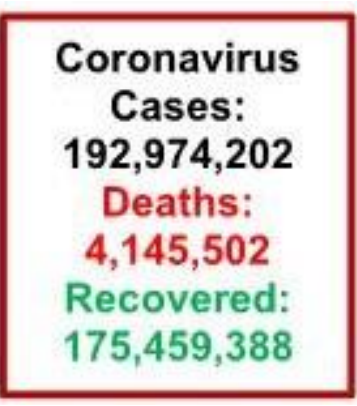

With this level of death, we can consider quite a few million children were left behind. How can we turn what is coming after this pandemic into an opportunity? The way some countries have turned some severe episodes of their history into "lessons learned" reconciliation, like the end of the civil or anti-terrorist war in Sri Lanka, like the reconciliation after the freeing of Nelson Mandela and the end of apartheid in South Africa.

In our field here, the teaching and learning of foreign languages, we can do it only if we consider teaching foreign languages is not a Public responsibility only but has to be dealt with as a Private-Public-Partnership bringing together the education system (both public and private), the various industrial partners we will need to conceive and design the Virtual Reality programs, the hardware and software necessary, and many other partners organized in various ways like parents, intellectuals, researchers, politicians, etc. We have also to deal 
with the project at the global level of the planet, and thus to bring into the project UNESCO, UNICEF, the United Nations Organization, the International Labor Organization, the World Health Organization, the World Trade Organization, the World Intellectual Property Organization, and probably some more like the European Union and other regional political or economic organizations, alliances of many types. I also think it would be absolutely vain if we did not associate to this project, representatives of the various religions, whose role will have to be negotiated. But beyond all these partners we have to also associate all the world's economic companies that can work on the conception, design, and production of all the various machines, hardware, and software needed for such a project, and with the widest possible open attitude, refusing to limit ourselves to the companies from this or that country. We need the concerned companies from absolutely all countries that have such companies within their borders.

Let's have a final thought to the victims of this ^pandemic, hoping the several hundred million vaccinations that have not been performed on as many children will be caught up and will have no nasty consequence like a sudden pandemic of polio or tetanus, or diphtheria.

COVID-19 Cases · Last updated: 30 mins ago, July 22, 2021, circa 12.00

Total $\oplus$ Worldwide

\begin{tabular}{|c|c|c|c|}
\hline Location & Cases & Recovered & Deaths \\
\hline United States & $\begin{array}{c}34.2 \mathrm{M} \\
4,200,000 \\
+60,838\end{array}$ & - & $\begin{array}{c}610 \mathrm{~K} \\
610,000 \\
+397\end{array}$ \\
\hline 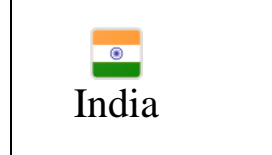 & $\begin{array}{l}31.3 \mathrm{M} \\
1,300,000 \\
+41,383\end{array}$ & $\begin{array}{c}30.4 \mathrm{M} \\
30,400,000 \\
+38,652\end{array}$ & $\begin{array}{c}419 \mathrm{~K} \\
419,000 \\
+507\end{array}$ \\
\hline Brazil & $\begin{array}{c}19.5 \mathrm{M} \\
9,500,000 \\
+54,517\end{array}$ & $\begin{array}{c}17.4 \mathrm{M} \\
17,400,000 \\
+33,430\end{array}$ & $\begin{array}{c}546 \mathrm{~K} \\
546,000 \\
+1,424\end{array}$ \\
\hline Russia & $\begin{array}{c}5.96 \mathrm{M} \\
5,960,000 \\
+23,164\end{array}$ & $\begin{array}{c}5.34 \mathrm{M} \\
5,340,000 \\
+22,221\end{array}$ & $\begin{array}{c}148 \mathrm{~K} \\
148,000 \\
+772\end{array}$ \\
\hline France & $\begin{array}{c}5.91 \mathrm{M} \\
5,910,000 \\
+21,539\end{array}$ & - & $\begin{array}{c}112 \mathrm{~K} \\
112,000 \\
+22\end{array}$ \\
\hline hited Kingdom & $\begin{array}{c}5.56 \mathrm{M} \\
5,560,000 \\
+43,404\end{array}$ & - & $\begin{array}{c}129 \mathrm{~K} \\
129,000 \\
+73\end{array}$ \\
\hline $\begin{array}{c}\text { C* } \\
\text { Turkey }\end{array}$ & $\begin{array}{c}5.55 \mathrm{M} \\
5,550,000\end{array}$ & $\begin{array}{c}5.4 \mathrm{M} \\
5,400,000\end{array}$ & $\begin{array}{l}50,650 \\
50,650\end{array}$ \\
\hline
\end{tabular}




\begin{tabular}{|c|c|c|c|}
\hline Location & Cases & Recovered & Deaths \\
\hline Argentina & $\begin{array}{c}4.8 \mathrm{M} \\
4,800,000 \\
+14,632\end{array}$ & $\begin{array}{c}4.43 \mathrm{M} \\
4,430,000 \\
+10,876\end{array}$ & $\begin{array}{c}103 \mathrm{~K} \\
103,000 \\
+437\end{array}$ \\
\hline Colombia & $\begin{array}{c}4.68 \mathrm{M} \\
4,680,000 \\
+11,244\end{array}$ & $\begin{array}{c}4.44 \mathrm{M} \\
4,440,000 \\
+12,684\end{array}$ & $\begin{array}{c}117 \mathrm{~K} \\
117,000 \\
+351\end{array}$ \\
\hline Italy & $\begin{array}{c}4.3 \mathrm{M} \\
4,300,000 \\
+4,254\end{array}$ & $\begin{array}{c}4.12 \mathrm{M} \\
4,120,000 \\
+2,235\end{array}$ & $\begin{array}{c}128 \mathrm{~K} \\
128,000 \\
+21\end{array}$ \\
\hline Spain & $\begin{array}{c}4.22 \mathrm{M} \\
4,220,000 \\
+30,587\end{array}$ & $\begin{array}{c}150 \mathrm{~K} \\
150,000\end{array}$ & $\begin{array}{c}81,166 \\
81,166 \\
+18\end{array}$ \\
\hline Germany & $\begin{array}{c}3.76 \mathrm{M} \\
3,760,000 \\
+1,651\end{array}$ & $\begin{array}{c}3.64 \mathrm{M} \\
3,640,000 \\
+830\end{array}$ & $\begin{array}{c}91,466 \\
91,466 \\
+43\end{array}$ \\
\hline $\bar{\Phi}$ & $\begin{array}{c}3.6 \mathrm{M} \\
3,600,000 \\
+27,379\end{array}$ & $\begin{array}{c}3.19 \mathrm{M} \\
3,190,000 \\
+17,112\end{array}$ & $\begin{array}{c}87,837 \\
87,837 \\
+213\end{array}$ \\
\hline Indonesia & $\begin{array}{c}2.98 \mathrm{M} \\
2,980,000 \\
+33,772\end{array}$ & $\begin{array}{c}2.36 \mathrm{M} \\
2,360,000 \\
+32,887\end{array}$ & $\begin{array}{l}77,583 \\
77,583 \\
+1,383\end{array}$ \\
\hline Poland & $\begin{array}{c}2.88 \mathrm{M} \\
2,880,000 \\
+124\end{array}$ & $\begin{array}{c}2.65 \mathrm{M} \\
2,650,000 \\
+31\end{array}$ & $\begin{array}{c}75,222 \\
75,222 \\
+3\end{array}$ \\
\hline Mexico & $\begin{array}{c}2.69 \mathrm{M} \\
2,690,000 \\
+15,198\end{array}$ & $\begin{array}{c}2.11 \mathrm{M} \\
2,110,000 \\
+8,517\end{array}$ & $\begin{array}{c}237 \mathrm{~K} \\
237,000 \\
+397\end{array}$ \\
\hline South Africa & $\begin{array}{c}2.33 \mathrm{M} \\
2,330,000 \\
+16,240\end{array}$ & $\begin{array}{c}2.1 \mathrm{M} \\
2,100,000 \\
+13,699\end{array}$ & $\begin{array}{c}68,192 \\
68,192 \\
+516\end{array}$ \\
\hline Ukraine & $\begin{array}{c}2.32 \mathrm{M} \\
2,320,000 \\
+1,195\end{array}$ & $\begin{array}{c}2.25 \mathrm{M} \\
2,250,000 \\
+940\end{array}$ & $\begin{array}{c}55,245 \\
55,245 \\
+24\end{array}$ \\
\hline
\end{tabular}




\begin{tabular}{|c|c|c|c|}
\hline Location & Cases & Recovered & Deaths \\
\hline Peru & $\begin{array}{c}1.98 \mathrm{M} \\
1,980,000\end{array}$ & $\begin{array}{c}1.94 \mathrm{M} \\
1,940,000\end{array}$ & $\begin{array}{c}187 \mathrm{~K} \\
187,000\end{array}$ \\
\hline Netherlands & $\begin{array}{c}1.82 \mathrm{M} \\
1,820,000 \\
+6,897\end{array}$ & - & $\begin{array}{c}17,786 \\
17,786 \\
+3\end{array}$ \\
\hline Czechia & $\begin{array}{c}1.67 \mathrm{M} \\
1,670,000 \\
+313\end{array}$ & $\begin{array}{c}1.64 \mathrm{M} \\
1,640,000 \\
+332\end{array}$ & $\begin{array}{c}30,342 \\
30,342 \\
+1\end{array}$ \\
\hline
\end{tabular}

Who could have said in 2019 the world would have changed so fast in just two years?

\section{BIBLIOGRAPHY}

[1] ---, Bradford College, Great Horton Rd, Bradford BD7 1AY

[2] ---, BTS Audio-Visuel, Lycée Jean Rostand, 361, Grande Rue, 59100 Roubaix

[3] ---, Foundation Charter of the Abbey of Tihany, 1054

[4] ---, Le Louvre, rue de Rivoli, 75001 Paris, Enjoy the Louvre at home, https://www.louvre.fr/en/onlinetours

[5] ---, M.A.K. Halliday, Encyclopedia Britannica, https://www.britannica.com/biography/MichaelHalliday

[6] ---, National Science and Media Museum, formerly National Museum of Photography, Film, and Television, Pictureville, Bradford, BD1 1NQ

[7] ---, Nursery Rhymes, The Farmer in the Dell, 1820

[8] ---, The Royal National Theatre, Registered Office: Upper Ground, London SE1 9PX (https://www.nationaltheatre.org.uk/shows/paradise

[9] ---, Palace of Berlin, Humboldt Forum, Schlossplatz, 10178 Berlin, https://www.humboldtforum.org/en/visit/virtual-visit/

[10] Noam Chomsky, Syntactic Structures, Cambridge, Massachusetts: MIT Press, 1957

[11] Jacques Coulardeau, SIGIRI GRAFFITI, Bilingual French-English edition, Editions La Dondaine, KINDLE DIRECT PUBLISHING, Amazon, September 3, 2013

[12] Jacques Coulardeau, SHADOW IN THE NIGHT, SIGIRIYA SHINY LADIES, Bilingual English \& French edition, Translated from the Sigiri Graffiti of Sigiriya, Historical English and French Introduction, KINDLE DIRECT PUBLISHING, Amazon, July 13, 2014

[13] Jacques Coulardeau, THE INDIAN OCEAN FROM ADMIRAL ZHENG HE TO HUB AND SPOKE CONTAINER MARITIME COMMERCE, co-auteur Ivan EVE, KINDLE DIRECT PUBLISHING, Amazon, Janvier 2016,

[14] Jacques Coulardeau, Freedom of Expression and Copyright (1100-2016), The Foundations of All liberties, (Research, 210 pages), Editions La Dondaine, Language: English, KINDLE DIRECT PUBLISHING, Amazon, March 13, 2017

[15] Jacques Coulardeau, Freedom of Expression and Copyright (1100-2016), The Foundations of All liberties, (Documents, 550 pages) Free Open Access https://www.academia.edu/31829015/Freedom_of_Expression_and_Copyright_The_Foundations_of_ All_Liberties, uploaded March 12, 2017

[16] Jacques Coulardeau, Co-author Ivan EVE, Cro-Magnon's Language, Emergence Of Homo Sapiens - Invention Of Articulated Language - Phylogeny Of Language - Migrations Out Of Africa Three Articulations - Three Linguistic Families, Editions La Dondaine, KINDLE DIRECT PUBLISHING, Amazon, 760 pages, ASIN: B074DXJM5C 2017 
[17] Jacques Coulardeau, "No Cognition Without Communication," in Psychology Research, Volume 8, Number 9, September 2018 (Serial Number 87), David Publishing Company, www.davidpublisher.com, open access http://www.davidpublisher.com/index.php/Home/Article/index?id=36921.html

[18] Jacques Coulardeau, "Cognition Is Communication, Cognition," in Studii-de-Știinta-și-Cultură Volumul XIV $\quad-\quad$ Numarul 3 (54) 2018, https://www.researchgate.net/publication/328887669_COGNITION_IS_COMMUNICATION

[19] Jacques Coulardeau, "Guided Self Learning," International Journal of Family Business and Management, Symbiosis Group, Normal, IL 61761, USA, February 1, 2019, open access https://symbiosisonlinepublishing.com/family-business-management/family-businessmanagement23.pdf

[20] Jacques Coulardeau, "Mind-Language, the Expanding Heart of Cognition," in Open Journal of Social Sciences, Volume 6, Number 6, June 2018, ISSN 2327-5952, pp. 32-47, Scientific Research Publishing Inc., SCIRP.org, Wuhan 430223, Hubei Province, China, 2018, DOI: $10.4236 /$ jss.2018.66004

[21] Jacques Coulardeau, "Phylogeny Commands Psychogenesis" in Studia Universitatis BabesBolyai Philologia LXIV, 4, December 2019, p. 37-58, DOI:10.24193/subbphilo.2019.4.02, ClujNapoca, Romania, December 15, 2019

[22] Jacques Coulardeau, "Phylogeny Commands Psychogenesis" in Repères-Dorif, n. 20 Modèles Linguistiques et cognitifs et didactique des langues, Do.Ri.F Università, Centro di documentazione e di Ricerca per la didattica della lingua francese nell'Università italiana, Roma, Italia, January 2020

[23] Jacques Coulardeau, Paleolithic Women, For Gendered Linguistic Analysis, Alexander Marshack - The Roots Of Civilization - Revised And Augmented Edition - 1991 - A Review (English Edition) KINDLE DIRECT PUBLISHING, Amazon, 80 pages, Éditions La Dondaine, 8 January 2020

[24] Jacques Coulardeau, AI, Unavoidable \& Unforgivable Tool, aka Make Friends With Translators, KINDLE DIRECT PUBLISHING, Amazon, Éditions La Dondaine, November 4, 2020, 277 pages.

[25] Jacques Coulardeau, Shakespearian Addiction, 264 pages, English, KINDLE DIRECT PUBLISHING, Amazon, Éditions La Dondaine, 15 February 2020, English, Shakespearian Addiction Extra Resources, https://www.researchgate.net/publication/339285977_Shakespearian_Addiction_Extra_Resources Open Access

[26] Jacques COULARDEAU, "Women's Role And Position In The Emergence Of Homo Sapiens," https://ifiasa.org/gallery/5th.11-2020mcdsare-jacques-coulardeau.pdf, in Conference: MCDSARE, Volume 4, Year 2020, https://doi.org/10.26520/mcdsare.2020.4,102-122, OPublished by IFIASA, Romania, Marin BUGIULESCU, editor, IFIASA, http://ifiasa.org/en/MCDSARE-2020 The Proceedings Volume of the 5th International Multidisciplinary Scientific Conference on the Dialogue between Sciences \& Arts, Religion \& Education Cover Page, Open Access

[27] Jacques COULARDEAU, 'Can Julien D’huy's Cosmogonies Save Us From Yuval Noah Harari?’ http://peijes.com/gallery/no.4-year3-2021-1-proedu-jacques\%20coulardeau.pdf, in Pro Edu. International Journal of Educational Sciences, e- ISSN 2668-5825 p- ISSN 2668-5817, Number 4, Year III, January 2021, https://peijes.com, OIFIASA, Ideas Forum International Academic and Scientific Association, pp.5-34, Open Access

[28] Council of Europe, Common European Framework of Reference for Languages: Learning, teaching, assessment, https://www.coe.int/en/web/common-european-framework-reference-languages

[29] David Fincher, Se7en, New Line Cinema, 1995

[30] Joseph Dichy, «L'enseignement de l'arabe est issu d'une tradition séculaire et prestigieuse », Le Parisien, 16 September 2018, https://www.leparisien.fr/societe/l-enseignement-de-1-arabe-est-issu-dune-tradition-seculaire-et-prestigieuse-16-09-2018-

7890279.php\#: :text=Le\%20nombre\%20d'enseignants\%20d,agr\%C3\%A9gation\%20et\%20quatre\%2 0au\%20Capes

[31] Denis Girard, Enseigner les langues: méthodes et pratiques, Bordas, Paris, 1995 
[32] Gustave Guillaume, Temps et verbe. Théorie des aspects, des modes et des temps suivi de L'architectonique du temps dans les langues classiques, Honoré Champion, Paris, 1984 (original 1929)

[33] MAK Halliday, Angus McIntosh \& Peter Strevens, The Linguistic Sciences, and Language Teaching, Longmans, London, 1964.

[34] M.A.K. Halliday, Introduction to Functional Grammar, Fourth Edition, 2014, Revised by Christian M.I.M. Matthiessen, Third edition published in 2004 by Hodder Education, a Hachette UK company. The fourth edition was published in 2014 by Routledge 2 Park Square, Milton Park, Abingdon, Oxon OX14 4RN. Simultaneously published in the USA and Canada by Routledge 711 Third Avenue, New York, NY 10017. (C) 1985, 1994, 2004, 2014 M.A.K. Halliday and Christian M.I.M. Matthiessen

[35] Ray Jackendoff, Semantic Interpretation in Generative Grammar, Cambridge, Massachusetts: MIT Press, 1972

[36] Ben Jonson, The Cambridge Edition of the Books of Ben Jonson online, Cambridge University Press, https://universitypublishingonline.org/cambridge/benjonson/

[37] Tony Kaye, American History X, New Line Cinema, 1998

[38] Jan Amos Komenský; aka John Amos Comenius, Comenius Foundation, https://www.comeniusfoundation.org/

[39] Baz Luhrman, Romeo + Juliet, Bazmark Production, 1996

[40] Jean-Baptiste Lully \& Madame de Brinon, God Save the King, a prayer for Louis XIV, Versailles, 1686.

[41] William Francis Mackey, Language Teaching Analysis, Longmans, London, 1965

[42] Christopher Marlowe, The Complete Works of Christopher Marlowe (5 Vols), The Marlowe Society, http://www.marlowe-society.org/christopher-marlowe/links-readings-etc/marlowebiographies/editions-of-marlowes-collected-works/

[43] André Martinet, Éléments de linguistique générale, Paris, Armand Colin, 1960.

[44] Gioachino Rossini, "Duetto para dos Gatos - Duet for Two Cats," https://www.youtube.com/watch?v=FJDtCw0MTNU

[45] Bertrand Russell, The Analysis of Mind, 1921, London and Beijing, https://www.gutenberg.org/files/2529/2529-h/2529-h.htm

[46] Ferdinand de Saussure, Course in General Linguistics, 1916

[47] William Shakespeare, Complete Works of William Shakespeare, Created by Jeremy Hylton, jeremy@alum.mit.edu, Operated by The Tech, MIT's oldest and largest newspaper, http://shakespeare.mit.edu/

[48] Daniel Tammet, Born on a Blue Day: Inside the Extraordinary Mind of an Autistic Savant, Free Press, October 16, 2007).

[49] TOEIC, Test of English for International Communication, https://www.ets.org/toeic

[50] John Trim \& al, Systèmes d'apprentissage des langues vivantes par les adultes, Systems for adult learning of modern languages, 1973

[51] Jon Turteltaub, Cool Runnings, Walt Disney Pictures, 1993 